EstAg 33 (1998) 227-270

\title{
Estructura de la Regla de san Agustín (III)*
}

\subsection{El libro décimo de las Confesiones ${ }^{1}$}

El libro décimo de las Confessiones constituye uno de los textos más bellos que dejó escritos san Agustín. Los estudiosos del monacato no suelen detenerse en él; sólo su último parágrafo despierta algún interés ${ }^{2}$. Nosotros creemos que el libro en su totalidad puede ayudar a comprender la Regla. Veamos en qué manera.

Como estructura del mismo bien podía aceptarse la siguiente: a) Una introducción (1,1-5,7); una primera sección (A) que consiste en un largo, y a veces lento, proceso de ascensión a Dios $(6,8-27,38)$; una segunda sección (B) en que examina su conciencia respecto de las tres concupiscencias, que tiran de él hacia abajo y le impiden mantenerse unido a Dios $(28,39-41,66)$; una tercera sección (C) en que presenta la función mediadora de Cristo (42,67$43,69)$; b) un epílogo, que contiene una confesión y decisión personal.

Si la estructura es esa, y no creemos que se pueda discutir ${ }^{3}$, llama la atención que coincida exactamente con la que L. Verheijen estableció para la Regla, anteriormente señalada. A partir de aquí, ¿cabe pensar que cada una de las secciones se corresponda con la respectiva de la Regla? En principio no hay que descartarlo. En las páginas que siguen trataremos de comparar ambos textos. Seguiremos el mismo método empleado a propósito del DVR: cotejar sección por sección, y dentro de ellas, cuando proceda, unidad por unidad.

\subsubsection{Comparación entre las secciones A de C10 y de la Regla}

A diferencia de lo que constatamos a propósito del DVR, existe una correspondencia entre las secciones de la Regla y las de C10. Esta circuns-

* Cfr. Estudio Agustiniano 32 (1997) 407-430; 33 (1998) 5-53.

1. En adelante $\mathrm{C} 10$.

2. Conf. 10,43,70 CC 27,193. Cf. A. DE VoGUÉ, Histoire littéraire, 3,208.

3. A lo más, cabría pensar si no sería preferible incluir 43,70 dentro de la sección C, antes que considerarlo a parte como un epílogo. En todo caso, se pueden separar en cuanto que lo anterior expone la doctrina, y 43,70 la aplicación por Agustín mismo en referencia a su propia persona de la doctrina anterior. 
tancia ayudará, sin duda, al lector y le ahorrará el esfuerzo de seguir razonamientos que se refieren a dos secciones de idéntico contenido, pero con numeración diferente.

La sección A de C10 se corresponde con los capítulos 6,8-27,38. Señalamos antes que su contenido consiste en un largo proceso de ascensión a Dios. Este se desarrolla según el esquema platónico -tan familiar para él-que parte del mundo exterior y pasa por el interior del hombre para llegar a lo que le transciende 4 . El término del proceso no es otro que Dios, reconocido como Verdad presente en el espíritu humano, y descubierto como Belleza siempre antigua y siempre nueva. Una Belleza que le ha asaltado por los cinco sentidos interiores y le ha permitido tener una experiencia inicial de ella. Esta experiencia no ha apagado su ansia, sino que la ha encendido todavía más. Le ha dejado deseoso de una más intensa posesión y le hace añorar el momento en que, por la posesión plena y definitiva, alcance la paz en Él. De hecho, esta parte acaba con el deseo de esa paz, in pacem tuam 5 .

Si ahora leemos el primer capítulo de la Regla, advertimos en él tres contenidos principales: a) la tensión hacia Dios (in Deum); b) La unidad de almas y corazones (completada con la posesión en común de los bienes) 6 ; c) el honrar a Dios en los demás que son templos de Él 7. Ahora bien, de los tres sólo el primero, el in Deum, se encuentra en la sección A de C10. Aunque falta la fórmula en su literalidad, toda la sección está impulsada por un dinamismo in Deum; por otra parte, el contenido del in pacem tuam de $\mathrm{C}^{10} 0^{8}$ remite al deseo de reposo en Dios del comienzo de la obra ${ }^{9}$ y no es otra cosa que lo significado por el in Deum de la Regla.

¿Qué decir de los otros dos puntos? ¿Están ausentes de C10? En ningún modo. Mas, para detectar su presencia, se nos impone abandonar la sección

4. Cfr. S. PÔQUE, L'expression de l'anabase plotinienne dans la prédication de saint Augustin et ses sources, en Recherches Augustiniennes 10 (1975) 187-215.

5. Se trata del conocido texto de 10,27,38, «qui est l'un des sommets des Confessions et de l'oeuvre de saint Augustin toute entière» (L. Verheijen, Comme des amants... Dans Augustin évêque..., p. 108; NA II,137): «Sero te amaui, pulchritudo tam antiqua et tam noua, sero te amavi!... Vocasti et clamasti et rupisti surditatem meam, coruscasti, splenduisti et fugasti caecitatem meam, flagrasti, et duxi spiritum et anhelo tibi, gustaui et esurio et sitio, tetigisti me, et exarsi in pacem tuam» (CC 27,175).

6. «...cor unum et anima una» (R I,2); «... unianimiter et concorditer uiuite» $(\mathrm{R} I, 8)$.

7. «Honorate in uobis inuicem deum cuius templa facti estis» $(I, 8)$.

8. Cf. M. Schrama, Praeposito tamquam patri oboediatur. Augustinus über Frieden und Gehorsam, en Augustiniana 41 (1991) 847-878. " "Friede" ist der Begriff, mit dem Augustinus die Vollendung all unserer Güter in höchsten Gut zum Ausdruck bringen will» (p. 849).

9. Conf. 1,1,1 CC 27,1: «... fecisti nos ad te et inquietum est cor nostrum donec requiescat in te». 
A y centrar la mirada en la introducción. Tampoco aquí se da coincidencia de términos, pero sí de conceptos. En la sección introductiva al libro san Agustín indica que no quiere recorrer el camino solo. Si, después de haber manifestado su pasado en los primeros nueve libros de las Confessiones, aceptó la petición que le fue dirigida de confesar su situación en el presente, lo hizo con el propósito de acompañar a los hermanos y sentirse acompañado por ellos en los logros y en los fracasos.

a) Acompañarlos con la lección de la propia experiencia. Así escribe:

«Este es el fruto de mis confesiones, no de lo que he sido, sino de lo que soy. Que yo confiese esto, no solamente delante de Ti..., sino también en los oídos de los creyentes, hijos de los hombres, compañeros de mi gozo y consortes de mi mortalidad, ciudadanos míos y peregrinos conmigo, ya me precedan, ya me sigan, ya caminen a mi lado. Estos son tus siervos, mis hermanos, que siendo hijos tuyos quisiste que fuesen señores míos, y a quienes me mandaste que sirviese, si quería vivir contigo de $\mathrm{Ti}{ }^{10}{ } 11$.

Y en un capítulo anterior:

«Hazme ver con qué fruto hago yo esto. Porque las confesiones de mis males pretéritos..., cuando son leídas y oídas, excitan el corazón para que no se duerma en la desesperación y diga: "No puedo", sino que le despierte al amor de tu misericordia y a la dulzura de tu gracia...» 12 .

b) Sentirse acompañado:

«Pero ¿qué fruto esperan sacar de esta pretensión? ¿Acaso desean unirse a mi acción de gracias al oír cuánto me he acercado a ti por don tuyo, y orar por mí Deum.

10. Este «vivir contigo de ti» tiene probablemente sentido escatológico, asociado al in

11. «Hic est fructus confessionum mearum, non qualis fuerim, sed qualis sim, ut hoc confitear non tantum coram te..., sed etiam in auribus credentium filiorum hominum, sociorum gaudii mei et consortium mortalitatis meae, ciuium meorum et mecum peregrinorum, praecedentium et consequentium et comitum uitae meae. Hi sunt serui tui, fratres mei, qui filios tuos esse uoluisti dominos meos, quibus iussisti ut seruiam, si uolo tecum de te uiuere» (Conf. 10,4,6 CC 27,157).

12. «... quo fructu ista faciam, eliqua mihi. Nam confessiones praeteritorum malorum meorum, quae remisisti et texisti, ut beares me in te, mutans animam meam fide et sacramento tuo, cum leguntur et audiuntur, excitant cor, ne dormiat in desperatione et dicat: "Non possum", sed euigilet in amore misericordiae tuae et dulcedine gratiae tuae...» (Conf. 10,3,4 CC 27,156). 
al oír cuánto me retardo por culpa de mi propio peso? A personas como esas me manifestaré. Pues no es pequeño fruto, Señor Dios mío, el que muchos te den gracias por mí $(2$ Cor 1,11$)$ y muchos te rueguen por mí. Que su espíritu fraterno ame en mí lo que enseñas que hay que amar, y que deplore en mí lo que enseñas que hay que deplorar. Esto sólo cabe en un espíritu fraterno, nunca en un espíritu extraño...; el espíritu fraterno que, cuando aprueba algo en mí, se llena de gozo por mí, y cuando desaprueba algo en mí se entristece por mí, porque ya me apruebe, ya me desapruebe, me ama» 13 .

Además de querer que los hermanos le acompañen en su recorrido de gratitud y súplica hacia Dios, presenta tal comportamiento como un acto de culto al Señor. El texto continúa así:

«A personas como esas me manifestaré. Respiren ante mis bienes, suspiren ante mis males. Mis bienes son obras y dones tuyos, mis males son culpas mías y condenas tuyas. Respiren ante los primeros y suspiren ante los segundos, y el himno y llanto suban a tu presencia desde los corazones fraternos, turíbulos que te inciensan. Mas tú, Señor, deleitado con la fragancia de tu santo templo, compadécete de mí, según tu gran misericordia (Sal 50,3), por amor de tu nombre» 14.

La imagen es inequívocamente cultual. Menciona, en efecto, el templo de Dios -los hermanos unidos a él en la acción de gracias y en la súplica de perdón-, los incensarios -los corazones de los hermanos-, la fragancia del incienso -lo que sale de los corazones: los himnos, el respirar ante los bienes presentes en él, y el llanto, el suspirar ante sus males-. Los mismos himnos y el llanto (cf. J1 2,17) son elementos tradicionales en el culto ${ }^{15}$. Los hermanos rin-

13. «Sed quo fructu id uolunt? An congratulari mihi cupiunt, cum audierint quantum ad te accedam munere tuo, et orare pro me, cum audierint, quantum retarder pondere meo? Indicabo me talibus. Non enim paruus est fructus, domine Deus meus, ut a multis tibi gratias agantur de nobis (2 Cor 1,11), et a multis rogeris pro nobis. Amet in me fraternus animus quod amandum doces, et doleat in me quod dolendum doces. Animus ille hoc faciat fraternus, non extraneus..., sed fraternus ille, qui cum approbat me, gaudet de me, cum autem improbat me, contristatur pro me, quia siue approbet, siue improbet me, diliget me» (Conf. 10,4,5 CC 27,157).

14. «Indicabo me talibus; respirent in bonis meis, suspirent in malis meis. Bona mea instituta tua sunt et dona tua; mala mea delicta mea sunt et iudicia tua. Respirent in illis et suspirent in his, et hymnus et fletus ascendant in conspectum tuum de fraternis cordibus, turibulis tuis. Tu autem, Domine, delectatus odore templi sancti tui, miserere mei secundum magnam misericordiam tuam (Ps 50,3) propter nomen tuum et nequaquam deserens caepta tua consumma imperfecta mea» (Conf. 10,4,5 CC 27,157).

15. De serm. Dom. in monte 1,10,27: «Quodlibet enim munus offerimus Deo, sive prophetiam, sive doctrinam, sive orationem, sive hymnum, sive psalmum...». Sobre el himno, cf. L. VERHEIJEN, Prier Dieu par des Psaumes et des "hymnes", en Augustiniana 37 (1987) 75-144; NA II, 290-322. 
den culto a Dios reconociendo sus dones en los bienes que posee Agustín y reconociendo las condenas divinas en sus males ${ }^{16}$.

He aquí el resultado de la comparación:

\section{Sección A 17: $^{17}$}

C10: Hacia tu paz.

Regla: Hacia Dios (R I,2).

C10: El espíritu fraterno que se une en la acción de gracias y en la súplica de perdón...

Regla: Unánimes y concordes; un alma sola y un solo corazón (R I,2.8).

C10: turíbulos, fragancia de tu santo templo.

Regla: honrad los unos en los otros a Dios (R I,8) ${ }^{18}$.

\subsubsection{Comparación entre las secciones $B$ de C10 y de la Regla}

La sección $\mathrm{B}$ de $\mathrm{C} 10$ nos ofrece un examen de conciencia personal de san Agustín respecto de las tres concupiscencias. Aunque él mantiene el orden en que las enumera san Juan, nosotros seguiremos aquel en que son tratadas en las distintas unidades de la sección B de la Regla, según expusimos anteriormente.

\subsubsection{Unidad primera}

Se ocupa de la concupiscencia de los ojos o curiosidad. El santo la describe como «la vana y curiosa concupiscencia, paliada con el nombre de conocimiento y ciencia, que radica en el alma a través de los mismos sentidos del cuerpo y que no consiste en deleitarse en la carne, sino en experimentar cosas

16. Cf. T. VAN BAVEL, "And honour God in one another» (Rule of Augustine 1,8), en Homo spiritalis. Festgabe für Luc Verheijen OSA zu seinem 70. Geburtstag. Herausgegeben von Cornelius Mayer unter Mitwirkung von K. H. Chelius, Würzburg 1987, pp. 196-20, en concreto, pp. 199-202.

17. Completada con datos de la introducción.

18. El mismo esquema en sus términos latinos:

C10: in pacem tuam $(10,27,38)$

Regla: in deum (R I,2)

C10: congratulari mihi / orare pro me; gaudet de me / contristatur pro me $(10,4,5) / /$ cives mei et mecum peregrini, comites uitae meae... $(10,4,6)$.

Regla: unianimes, anima una et cor unum (R I,2); unianimiter et concorditer $(\mathrm{R} I, 8)$.

C10: hymnus, fletus, turibula, odoratus templi...tui $(10,4,5)$

Regla: Honorate in uobis inuicem deum cuius templa facti estis» (R I,8). 
por mediación de la carne» ${ }^{19}$, o como «el apetito desordenado de experimentar y conocer» 20 . Luego presenta sus manifestaciones concretas con estas palabras:

«De esta enfermedad de la apetencia proviene el que se exhiban monstra et miracula 21 en los espectáculos; de ahí también el deseo de escrutar los secretos de la naturaleza, que está sobre nosotros y que no aprovecha nada conocer y que los hombres no desean más que conocer; de ahí proviene igualmente el que, con el mismo fin de un conocimiento perverso, se busque algo por medio de las artes mágicas; de ahí proviene, por último, el que se tiente a Dios en la misma religión, pidiéndole signos y prodigios, no para la salud de alguna persona, sino sólo por el deseo de verlos» 22 .

Tras señalar las manifestaciones mayores de dicha concupiscencia, pasa a examinarse a sí mismo al respecto. Confiesa estar libre de las mencionadas ${ }^{23}$, pero no de una infinidad de otras menores, de las que son sólo ejemplos las conversaciones vanas y una escena natural de caza que desvía su atención de pensamientos profundos ${ }^{24}$. Continúa así:

«Y ¿qué decir de las veces que, sentado en mi casa, me llama la atención una salamanquesa atrapando moscas o una araña envolviéndolas en su tela? ¿Es que, por ser pequeños estos animales, el efecto que producen no es idéntico? Es cierto que paso después a alabarte por ello, creador maravilloso y ordenador de todas las cosas, pero mi intención primera no ha sido esa. Una cosa es levantarse pronto y otra no caer.

De detalles como estos está llena mi vida. Mi única esperanza es tu extraordinaria misericordia. Porque cuando nuestro corazón se convierte en un asilo de tales cosas y alberga ese montón de vanidad, es perfectamente explicable que con frecuencia se interrumpan y perturben nuestras oraciones. Y, mientras en tu presencia dirigimos a tus oídos la voz, una bandada de pensamientos frivolos sale de no sé donde y corta en seco un acto de tanta importancia» 25 .

19. «Praeter enim concupiscentiam carnis... inest animae per eosdem sensus corporis quaedam non se oblectandi in carne, sed experiendi per carnem uana et curiosa cupiditas nomine cognitionis et scientiae palliata» (Conf. 10,35,54 CC 27,184).

20. «... experiendi noscendique libidine» (Conf. 10,35,55 CC 27,184-185).

21. Al respecto cf. M. TASINATO, Sulla curiositá. Apuleio e Agostino, Parma 1994, p. 28-29.

22. Conf. 10,35,55 CC 27,185.

23. Ib. $10,35,56 \mathrm{CC} 27,185$.

24. Ib. 10,35,57 CC 27,185-186.

25. «Quid cum me domi sedentem stelio muscas captans uel aranea retibus suis inhaerentes implicans saepe intentum me facit? Num quia parua sunt animalia, ideo non res eadem geritur? Pergo inde ad laudandum te, creatorem mirificum atque ordinatorem rerum omnium, 
Además de los grandes espectáculos como eran los del circo, anfiteatro o teatro, hay, pues, otra infinidad de ellos, de menor relieve en su aparatosidad externa. También estos satisfacen la concupiscencia de los ojos, y pueden producir en el alma el mismo efecto nocivo que los otros. Sobre todo en el acto tan importante de la oración: o bien la interrumpen, o bien la turban. De ceder ante ellos se lamenta el santo.

Es ya el momento de volver a la Regla y específicamente a su capítulo segundo. Es posible que en él el legislador, teniendo en cuenta su propia experiencia ${ }^{26}$, trate de prevenir ese mal en los monjes y disponga los medios para que su oración sea digna. En su parágrafo segundo dice así:

«En el oratorio nadie haga sino aquello para lo que ha sido destinado, de donde le ha venido el nombre; para que, si acaso hubiera algunos que, teniendo tiempo, quisieran orar fuera de las horas establecidas, no se lo impida quien pensara hacer allí otra cosa» 27.

Lo prescrito va dirigido a que nadie, por hacer en el oratorio lo que no debe, se constituya en impedimento para que los hermanos que, teniendo tiempo, quieran hacer oración, puedan hacerla debidamente. Ahora bien, se puede obstaculizar la oración obligando a interrumpirla (saepe interrumpuntur) o dificultando la concentración a quien ya está orando (atque turbantur). En este caso, cualquier actividad que allí se realice puede convertirse en un «espectáculo» menor que suscite la atención del siervo de Dios en oración y rompa su trato con Dios.

Todavía se puede ir más lejos. En el texto antes citado de 10,35,57, san Agustín mostraba las consecuencias concretas de la presencia de esos «espectáculos menores» para la oración. Según él, mientras se eleva la voz a Dios, una bandada de pensamientos frívolos sale de no sabe dónde y corta en seco acto tan importante. De esa manera, aunque materialmente se sigan recitando oraciones, la oración no existe en la práctica. Es otra forma de interrupción de la misma. En este contexto cuadra perfectamente la recomendación

sed non inde intentus esse incipio. Aliud est cito surgere, aliud est non cadere. Et talibus uita mea plena est, et una spes mea magna ualde misericordia tua. Cum enim huiuscemodi rerum conceptaculum fit cor nostrum et portat copiosae uanitatis cateruas, hinc et orationes nostrae saepe interrumpuntur atque turbantur, et ante conspectum tuum, dum ad aures tuas uocem cordis intendimus, nescio unde inruentibus nugatioriis cogitationibus res tanta praeciditur» (Conf. 10,35,57 CC 27,186).

26. Cf. al respecto también $E p .48,1$, de que hablaremos en su momento.

27. «In oratorio nemo aliquid agat nisi ad quod est factum, unde et nomen accepit; ut si forte aliqui, etiam praeter horas constitutas, si eis uacat, orare uoluerint, non eis sit impedimento, qui ibi aliquid agendum putauerit» (R II,2). 
que se lee en el tercer párrafo del capítulo segundo de la Regla: «Cuando oráis a Dios con salmos e himnos, que sienta el corazón lo que profiere la voz» ${ }^{28}$. Quizá no quiera decir más que esto: evitar que «la bandada de pensamientos frívolos» impida que se ore en verdad cuando se ora con salmos e himnos.

En esquema:

\section{Concupiscencia de los ojos:}

C10: a) [espectáculos menores exteriores] que interrumpen la oración.

b) [espectáculos interiores] que turban la oración.

Regla: a) [espectáculos menores exteriores:] quien piense hacer algo allí / no impida la oración (R II,2).

b) [espectáculos interiores] sienta el corazón lo que profiere la voz (R II,3) ${ }^{29}$.

No parece descabellado señalar, como resultado de la comparación, que el contenido del capítulo segundo de la Regla responde a algunas de las manifestaciones de la concupiscencia de los ojos, descritas en $\mathrm{C}^{30}{ }^{30}$. El legislador le dedica sólo un breve capítulo, en correspondencia quizá con el tratamiento que le asigna en $\mathrm{C} 10$, sin duda breve, si lo comparamos con la amplitud con que trata las otras dos concupiscencias.

28. «Psalmis et hymnis cum oratis deum, hoc uersetur in corde quod profertur in uoce» (R II,3).

29. El mismo esquema en términos latinos:

Concupiscentia oculorum:

C10: a) [spectacula exteriora:] orationes interrumpuntur

b) [spectacula interiora:] orationes turbantur

Regla: a) [spectacula exteriora:] qui aliquid agendum putauerint/non eis sit impedimento

b) [spectacula interiora:] uersetur in corde quod profertur in uoce.

30. A partir de aquí habría que matizar numerosos juicios sobre este segundo capítulo de la Regla. Para A. Trapé la oración (R II), la mortificación (R III,1), la lectio divina (R III,2), el estudio y el trabajo ( $\mathrm{R} \mathrm{V}$ ) son el continuo alimento de la caridad (La Regola 178). No lo discutimos, pero dudamos mucho que ese sea el criterio que mantiene unidos todos esos capítulos, además de saltarse el cuarto. A. Zumkeller acentúa en el capítulo las disposiciones sobre la oración en común, así como el hecho de que el capítulo de la oración siga inmediatamente a la recomendacion de honrar a Dios los unos en los otros (R I,8) (Das Mönchtum des hl. Augustinus, p. 220); ambos aspectos pone de relieve también T. van Bavel (Regla para la comunidad, p. 48) y el segundo G. Colombás (La tradición benedictina, I, p. 404). Creemos que sólo materialmente son ciertas tales afirmaciones en el sentido de que no es ese el criterio que rige la sucesión de estos capítulos en la Regla. 


\subsubsection{Unidad segunda}

A propósito de la concupiscencia de los ojos, san Agustín sintió la necesidad de comenzar definiéndola o describiéndola. Decisión lógica porque, habiendo tratado inmediatamente antes del sentido de la vista dentro de la concupiscencia de la carne, el lector podía sentirse desorientado. En cuanto a la concupiscencia de la carne, da por supuesto que todos saben en qué consiste y cuáles son sus manifestaciones. En consecuencia, sin detenerse a definirla, pasa a examinarse respecto de cada una de sus manifestaciones. ¿Cuáles son estas?

En DVR san Agustín resumía las manifestaciones de la misma en el deseo de comer y beber, de mantener relaciones sexuales y de dormir. En C10 abandona este planteamiento y adopta como criterio el de los sentidos corpóreos. En su satisfacción indebida encuentra las diversas manifestaciones de dicha concupiscencia. El orden que establece entre los sentidos es el siguiente: tacto, gusto, olfato, oído y vista; orden establecido conforme a criterios de mayor o menor materialidad: en efecto, comienza con el sentido más material, el del tacto, para concluir con el menos, el de la vista 31. Para no multiplicar las páginas innecesariamente, nos eximimos de traer aquí lo que san Agustín dice respecto de cada uno de ellos ${ }^{32}$. La parte equivalente de la Regla se corresponde con los capítulos tercero y cuarto. Quien los lea con atención advertirá que en ellos se encuentra la actividad de todos los sentidos del cuerpo, a excepción del del olfato, que, sin embargo, no está ausente del documento monástico, aunque el Santo le asignará otra función, como se señalará en su momento. Veamos, pues, la presencia de esos cuatro sentidos en la parte señalada de la Regla.

\subsection{Sentidos del oído y del gusto}

Que el capítulo tercero de la Regla se ocupa del sentido del gusto es evidente, puesto que regula el comer y el beber. En su primer parágrafo prescribe el ayuno de comida y bebida, en el segundo ordena la lectura en el refectorio, y en los restantes establece la atención individualizada en función de la condición y salud de cada siervo de Dios. No es preciso que nos detengamos más.

31. Cf. I. Bocher, Saint Augustin et le désir de Dieu, Paris 1982, p. 42

32. El lector puede consultar directamente C10. Para el tacto, 30,41-42; para el del gusto; 31,43-47; para el del olfato, 10,32,48; para el del oído, 10,33,49-50; para el de la vista, 10,34,5153. 
El sentido del oído, en cambio, no aparece tan en primera línea, pero no está ausente. De hecho, aparece en R III,2, al ordenar la lectura en el refectorio: «para que no sea sola la boca la que recibe el alimento, sino que también el oŕdo sienta hambre de la palabra de Dios» ${ }^{33}$.

\subsection{Sentidos del tacto y la vista}

Si el capítulo tercero trata de evitar que el siervo de Dios quede prisionero de la uoluptas ${ }^{34}$ vinculada al sentido gusto (y del oído), el cuarto busca que no sucumba a la que tiene su fuente en el sentido del tacto. Cuando habla en forma genérica de este sentido, señala que percibe «lo duro o lo blando, lo caliente o lo frío, lo áspero o lo suave, lo pesado o lo ligero» ${ }^{35}$; pero cuando concreta, es frecuente que recurra al ámbito sexual como espacio privilegia-

33. «... nec solae uobis fauces sumant cibum sed et aures esuriant dei uerbum» (R III,2).

En el anterior artículo, ateniéndonos a la división, por otra parte tradicional, fijada en la edición crítica de L. Verheijen, consideramos R II,4 dentro de la unidad primera de la sección $\mathrm{B}$, es decir, encuadrada dentro del marco referido a la concupiscencia de los ojos y señalamos cuál podría ser -pura hipótesis- la relación de lo allí prescrito ( $Y$ no cantéis sino lo que leéis que hay que cantar; pero lo que no está escrito para ser cantado, que no se cante») con dicha concupiscencia (cf. Estructura [II], en Estudio Agustiniano 33 [1998] p. 25, nota 73). Cabría preguntarse, sin embargo, si no sería igual de acertado considerar dicho parágrafo formando parte de la unidad siguiente, referida ya a la concupiscencia de la carne. De esta manera tendríamos que el capítulo tercero seguiría «regulando» dos sentidos: el del oído (de forma más clara que la solución que acabamos de proponer) y el del gusto, igual que el cuarto regularía otros dos: el del tacto y el de la vista. Esta solución tiene la ventaja de que se ajusta bien a lo que dice en $\mathrm{C} 10$ a propósito de la música en el contexto de la concupiscencia de la carne. La música, aun la litúrgica, podría ser peligrosa, por la posibilidad de convertirse en instrumento al servicio de dicha concupiscencia a través del sentido del oído. Sólo es preciso recordar la fluctuación que manifiesta el santo respecto de ella: «Así fluctúo entre el peligro del placer y la experiencia de la salud que aporta» (Conf. 10,33,50 CC 27,182). Cf. A. VERHEuL, La spiritualité du chante liturgique chez saint Paul et saint Augustin, en Questions Liturgiques 64 (1983) 165-178). Tales palabras podrían explicar el texto de la Regla: de un lado, los siervos de Dios han de desear cantar sólo lo mandado, en atención al provecho espiritual que se puede obtener; de otro, no han de cantar lo que no está escrito para ser cantado, en atención al peligro que subyace en el placer, que puede justificar el canto por el canto mismo y no por motivos específicamente religiosos.

Cabría pensar incluso que san Agustín ha puesto intencionadamente ese parágrafo a cabaIlo entre los dos capítulos, esto es, entre las dos concupiscencias, como dando a entender que participa de la una y de la otra. También una actividad tan espiritual como la oración puede convertirse en campo abonado para la concupiscencia de la carne. Esta «doble militancia» no sería única en la Regla. Tenemos lo mismo en el capítulo sexto, donde el último parágrafo entra ya en territorio propio del capítulo séptimo y de esa manera lo anuncia y lo introduce.

34. «... nec ibi eos teneat uoluptas iam uegetos...» (R III,5).

35. Sermo 277,5,5: PL 38,1261. 
do para dicha sensación. Es el caso de $\mathrm{C} 10$ 36. Como tratamos de mostrar a propósito del DVR, en todos los preceptos del capítulo cuarto Agustín tiene en mente el tema de la castidad. Pero el aspecto sobre el que centra su atención es el de las miradas impuras. Detrás está, sin duda, la referencia a Mt 5,28: «Todo el que mira a una mujer deseándola, ya cometió con ella adulterio en su corazón». A través de la cita bíblica, ha introducido otro sentido, el de la vista. Estos dos sentidos, el del tacto y el de la vista, parecen estructurar el capítulo cuarto, al menos a partir del parágrafo cuarto, donde constata que «no sólo con el tacto (tactu ${ }^{37}$ )..., sino también con la mirada (aspectu ${ }^{38}$ ) se provoca y nos provoca el deseo de las mujeres 39.

De los cinco sentidos, pues, de que se sirve la concupiscencia de la carne, san Agustín se ha ocupado de cuatro de ellos: en el capítulo tercero, de los dos intermedios respecto del orden seguido en C10 (gusto y oído); en el cuarto, de los dos extremos (tacto y vista). Sólo está ausente el central, el del tacto. En principio, no extraña en la medida en que san Agustín trate de regular la vida de los siervos de Dios desde la que fue su experiencia personal. En C10 señala que el olfato es el sentido que menos problemas morales ocasiona y, en consecuencia, al que menos espacio dedica ${ }^{40}$. Pero no tardaremos en topar con él.

Todo dicho se puede resumir en este esquema:

\section{Concupiscencia de la carne}

C10: (sentido del tacto) relaciones sexuales y matrimonio $(30,41)$.

Regla: (sentido del tacto) no sólo con el tacto... aunque los cuerpos permanezcan intactos... (R IV). IV,4).

36. Cf. Conf. 10,30,41-42; también 4,7,12; 10,6,8; 10,27,38 CC 27,176-177. 46. 159. 175.

37. Cf. más adelante: «aun sin que haya contacto físico» (etiam intactis corporibus) ( $\mathrm{R}$

38. Además de esta, son muchas otras las referencias al sentido de la vista en este capítulo cuarto. IV,4: aunque vuestros ojos se encuentren con alguna mujer... (Oculi uestri, etsi iaciuntur in aliquam feminarum); no se os prohíbe ver a las mujeres (neque... feminas uidere prohibemini); si tenéis los ojos impuros, porque el ojo impuro... (si habetis oculos impudicos, quia impudicus oculus...); con la mutua mirada (conspectu mutuo); IV,5: el que fija la vista en alguna mujer y se deleita en ser mirado por ella (qui in femina figit oculum et illius in se ipse diligit fixum); es visto por quienes no piensa él que le ven (uidetur... et a quibus se uideri...); ... creer que no ve porque lo ve... (non uidere quia tanto uidet...); ... que todo lo ve... mirar con malicia a una mujer (omnia uidere... male videre...).

39. «Nec solo tactu et affectu, sed aspectu quoque, adpetitur et adpetit concupiscentia feminarum» $(\mathrm{R} I \mathrm{~V}, 4)$.

40. Sólo 10 líneas en la edición del CC, mientras que al sentido del tacto dedica 39, al del gusto 85 , al del oído $40 \mathrm{y}$ al de la vista 54 . 
C10: (sentido del gusto) ... comiendo y bebiendo $(31,43)$

Regla: (sentido del gusto) ... comida y bebida (R III)

C10: (sentido del olfato) el atractivo de los perfumes $(32,48)$

Regla: (sentido del olfato)

C10: (sentido del oído) ... los placeres de los oídos $(33,49)$

Regla: (sentido del oído) ... el oído sienta hambre (III,2); cf. también: cántese/no se cante (II,4).

C10: (sentido de la vista)... los deleites de estos ojos $(34,51)$

Regla: (sentido de la vista): vuestros ojos no se fijen... (IV,4) ${ }^{41}$.

La comparación entre C10 y la Regla da como resultado que los capítulos tercero y cuarto forman una unidad estructural, cuyo criterio unificador es la concupiscencia de la carne, que se manifiesta en los sentidos del oído, gusto, vista y tacto ${ }^{42}$. Dicha unidad recibe, en cuanto a extensión, un tratamiento amplio que se corresponde con el que recibe en $\mathrm{C} 10$.

\subsection{Unidad tercera}

Si los capítulos tercero y cuarto de la Regla constituyen una unidad estructural, lo mismo puede sostenerse a propósito de los capítulos quinto, sexto y séptimo, pero ahora con la tercera concupiscencia, la ambición mundana, como criterio unificador.

41. El mismo esquema en términos latinos:

Concupiscentia carnis:

C10: (sensus tactus) ... de concubitu et de... coniugio... (30,41-42 CC 27,176-177).

Regla: (sensus tactus) tactu/intactis; feminas appetere aut appeti uelle (R IV).

C10: (sensus gustus) ... edendo et bibendo (31,43-47 CC 27,177-180)

Regla: (sensus gustus) ieiunia et abstinentia escae et potus (R III).

C10: (sensus odoratus) De illecebra odorum (32,48 CC 27,180-181).

Regla: (sensus odoratus) ...

C10: (sensus auditus) Voluptates aurium (33,49-50 CC 27,181-182).

Regla: (sensus auditus) aures esuriant Dei uerbum (III,2); contetur/non cantetur (II,4).

C10: (sensus uisus) Voluptas oculorum istorum (34,51-53 CC 27,182-184).

Regla: (sensus uisus) ... oculi uestri figantur in nemine (R IV,4).

42. A. Sage prefiere unir los capítulos segundo y tercero apoyándose en Mc 9,29 (Vulg.) donde Cristo advierte que en ciertos combates sólo se triunfa con la oración y el ayuno ( $L a$ Regla, p. 55). Más adelante los une sobre el concepto de salud: «Si la oración asegura la perfecta salud al alma, la del cuerpo se obtiene mediante las mortificaciones; y así como la salud del alma repercute en la del cuerpo, así también la salud de este influye... en la del alma. Por esto motivo se nos presenta el ayuno como el complemento natural de la oración» (Ib. p. 65). 
El tratamiento de la ambición mundana en C10 ocupa cuatro capítulos (36-39), centrados en diversas manifestaciones del orgullo: el 36, en el afán de dominar; el 37 y 38 , en el deseo de alabanzas, y el 39, en la autocomplacencia.

En el primero de esos capítulos leemos:

«Por ventura, Señor, tú, el único que te enseñoreas sin orgullo, puesto que eres el único y verdadero Señor, que no tiene señor; por ventura me ha dejado o puede dejarme durante toda esta vida este tercer género de tentación, que consiste en querer ser temido y amado de los hombres, no por otra cosa, sino por conseguir un gozo que no es gozo?» 43 .

Poco más adelante continúa de esta manera:

«Mas como quiera que por ciertos oficios de la sociedad humana nos es necesario ser amados y temidos de los hombres, insiste el adversario de nuestra verdadera felicidad esparciendo en todas partes, cual lazos, estas palabras: "Bien, bien", para que ... nos agrade ser amados y temidos no por motivo tuyo, sino en tu lugar... Sé tú nuestra gloria; que se nos ame por causa de ti; que sea tu palabra la que se tema en nosotros» 44.

Aquí san Agustín delata el orgullo que consiste en la pretensión de dominar sobre los demás. La referencia inicial a Dios como el único Señor que no tiene señor sobre sí y en quien, por tanto, el enseñorearse no es manifestación de orgullo, así lo revela. El querer ser temido y amado en sí mismo no es más que el aflorar de esa pretensión. El hombre, que está sometido a Dios, su señor, y que por tanto no es propiamente señor, pretende ocupar el lugar de Dios y recabar el amor y el temor que sólo Él merece. Eso es poner en sí mismo y no en Dios la propia gloria, de donde surge el deseo de alabanza, es decir, de que los demás le reconozcan esa gloria. Es la tentación de aquellos que desempeñan ciertos cargos en la sociedad humana; en su caso, el de obispo de una comunidad eclesial. Propiamente, el orgullo no se manifiesta en el

43. «Sed numquid, Domine, qui solus sine typho dominaris, quia solus uerus dominus es, qui non habes dominum, numquid hoc quoque tertium temptationis genus cessauit a me aut cessare in hac tota uita potest, timeri et amari uelle ab hominibus non propter aliud, sed ut inde sit gaudium, quod non est gaudium?» (Conf. 10,36,59 CC 27,187).

44. «Itaque nobis, quoniam propter quaedam humanae societatis officia necessarium est amari et timeri ab hominibus, instat aduersarius uerae beatitudinis nostrae ubique spargens in laqueis euge, euge, ut, dum auide conligimus, incaute capiamur et a ueritate tua gaudium nostrum deponamus atque in hominum fallacia ponamus, libeatque nos amari et timeri non propter te, sed pro te... Gloria nostra tu esto; propter te amemur et uerbum tuum timeatur in nobis» (Conf. 10,36,59 CC 27,187). 
simple hecho de que quiera ser amado y temido, sino en que quiera serlo en sí mismo. Frente a este amor y temor perverso existen el amor y el temor recto: cuando el motivo del amor que se recibe es Dios y cuando el temor de que el obispo es objeto es propiamente temor a la palabra de Dios que, en cuanto ministro, proclama.

Esa pretensión de suplantar a Dios, constituyéndose en señor, tendrá sus repercusiones negativas en el momento del juicio definitivo. A quienes apetecen ser alabados por los hombres, vituperándoles Dios, el santo les recuerda que, cuando Él les juzgue, no serán ellos quienes salgan en defensa suya, ni le salvarán cuando Dios los condene ${ }^{45}$.

En un texto de la obra De doctrina christiana, contemporánea de las Confessiones, escribe Agustín: «Pueden ${ }^{46}$, por tanto, ver cuán arduo y difícil es no dejarse atrapar por el cebo de la alabanza, ni sentir el aguijón de las injurias» ${ }^{47}$. Con estas palabras indica el doble modo como la lengua ajena puede provocar el orgullo de una persona: con la alabanza o con la injuria.

A partir de aquí se puede entender mejor el capítulo 37 de C10. En él examina el santo su actitud frente a las alabanzas y a las vituperaciones e, incluso, injurias. Examen ciertamente difícil. Respecto de las alabanzas porque, para ver si las desprecia, tendría que conocer si puede pasar sin ellas. Lo cual le exigiría emprender el camino de una conducta réproba, algo totalmente desechable. De hecho, su examen no le permite ver todo lo claro que quisiera, porque no siempre sabe darse razón de cuanto acontece en su alma. Confiesa que la aprobación ajena aumenta el gozo por cualquier bien que posee y que la vituperación lo disminuye. Al respecto tranquiliza su conciencia con argumentos como este: «con frecuencia me parece que me deleito del provecho o esperanza del prójimo cuando me deleito con la alabanza de que me ha entendido bien (cuando predicaba), y a su vez, que me contristo con su mal cuando le oigo vituperar lo bueno que ignora» 48. Sólo que esa defensa pierde buena parte de su fuerza al constatar que, por ejemplo, le hiere más la

45. «Qui laudare uult ab hominibus uituperante te, non defendetur ab hominibus iudicante te nec eripietur damnante te» (Conf. 10,36,59 CC 27,187).

46. Se refiere a los maniqueos que, con referencia a los patriarcas del Antiguo Testamento, podrían defender que no conviene tributar honores ni alabanzas a los varones santos y buenos, porque se hincharían de soberbia.

47. «Videant ergo quam sibi arduum sit atque difficile, nec laudis esca illici nec contumeliarum aculeis penetrari» (De doctr. christ. 3,19,29 CC 32,95).

48. «... saepe mihi uideor de prouectu aut spe proximi delectari, cum bene intellegentis laude delector, et rursus eius malo contristari, cum eum audio uituperare quod aut ignorat aut bonum est» (Conf. 10,37,61 CC 27,189). 
afrenta lanzada contra él que la que, en su presencia, se lanza con la misma injusticia contra otra persona ${ }^{49}$.

El texto aporta algunos elementos, referidos por san Agustín a su propia persona: a) Se siente movido por el deseo de alabanza; b) esta alabanza se alimenta del reconocimiento por los demás de las propias buenas cualidades $u$ obras; c) por eso, la afrenta o injuria le produce una herida interior. Hasta aquí el caso personal. Pero conviene recordar que en el capítulo anterior, confiesa que ya le ha transformado parcialmente Dios, que le sana, en primer lugar, del deseo desordenado de venganza ${ }^{50}$. Por tanto, si hubiese expuesto el caso de otra persona menos comprometida con la fe, o de sí mismo en un momento anterior de su vida, el proceso hubiese continuado probablemente con los siguientes pasos: d) La herida recibida enciende la ira, acompañada de litigios y peleas; e) por último, la ira arde en deseos de venganza. Pura hipótesis, sin duda, pero creemos que lógica.

La complacencia en la alabanza recibida de otras personas puede ser reemplazada por la simple autocomplacencia, de que se ocupa el capítulo 39 . En la primera, el hombre depende de los demás, mendigando aquiescencias; en la segunda el hombre llega incluso a despreciarlas, muy satisfecho consigo mismo. Escribe, en efecto:

«También hay dentro de nosotros... y en este mismo género de tentación, otro mal con el que se desvanecen los que se complacen en sí mismos, aunque no agraden, o más bien desagraden, a los demás, ni tengan deseo alguno de agradarles. Mas estos tales, agradándose a sí mismos, te desagradan mucho a ti, no sólo teniendo por buenas las cosas que no lo son, sino poseyendo tus bienes como si fueran suyos propios; o, si tuyos, como debidos a sus méritos; o, si como debidos a tu gracia, no asociando a los demás en el disfrute de ellos, sino envidiándolos en otros» 51 .

Estamos ante una nueva forma de orgullo, cuya manifestación inmediata está en relación con las cosas y sólo indirectamente en relación con las per-

49. «Si utilitate proximi moueor in laudibus meis, cur minus moueor, si quisquam alius iniuste uituperetur quam si ego? Cur ea contumelia magis mordeor, quae in me quam quae in alium eadem iniquitate coram me iacitur? (Conf. 10,37,62 CC 27,187).

50. «Et tu scis, quanta ex parte mutaueris, qui me primitus sanas a libidine uindicandi me...» (Conf 10,36,58 CC 27,186).

51. «Intus... est aliud in eodem genere temptationis malum, quo inanescunt qui placent sibi de se, quamuis aliis uel non placeant uel displiceant nec placere affectent ceteris. Sed sibi placentes multum tibi displicent non tantum de non bonis quasi bonis, uerum etiam de bonis tuis quasi suis, aut etiam sicut de tuis, sed tamquam ex meritis suis, aut etiam sicut ex gratia tua, non tamen socialiter gaudentes, sed aliis inuidentes eam» (Conf. 10,39,64 CC 27,190). 
sonas. Es el orgullo que consiste en no reconocer los bienes como dones de Dios, sino como propiedad personal. De esa actitud primera surge luego, como consecuencia lógica, la otra de no querer compartirlos con los demás, de negarse a que los demás disfruten también de ellos (socialiter gaudentes) y de sentir envidia de lo que la gracia divina haya querido otorgar a otros (aliis inuidentes eam).

La comparación con la Regla resultará aquí tan fructífera como en los casos anteriores. Seguiremos el orden de los capítulos de la Regla incluidos dentro de esta unidad tercera.

El capítulo quinto remite al orgullo como autocomplacencia. Con referencia a esta forma de orgullo, acabamos de poner de relieve tres aspectos: el tomar como propiedad personal los bienes recibidos de Dios (de tuis bonis quasi suis); la negativa a gozar de ellos en compañía de los demás (non tamen socialiter gaudentes); el envidiar los dones de la gracia a los demás (aliis inuidentes eam). No es difícil encontrar los tres aspectos en el mencionado capítulo. Veámoslo.

Si algo muestra aborrecer el santo en él, es precisamente la conciencia de propiedad privada (propria), y, como reverso de la moneda, si algo promueve es la posesión en común de todo (commune). Nada mejor que trascribir en su totalidad el parágrafo segundo del capítulo:

«Y esto ha de ser de tal modo que ninguno trabaje en nada para sí mismo, sino que todos vuestros trabajos se realicen para la comunidad, con mayor cuidado y prontitud que si cada uno lo hiciera para sí. Porque la caridad de la que está escrito que no busca los propios intereses (1 Cor 13,5), se entiende así: que antepone lo común a lo particular, no lo particular a lo común. Por consiguiente, conoceréis que habéis adelantado en la perfección tanto más cuanto mejor cuidéis lo que es común que lo que es propio; de tal modo que en todas las cosas que utiliza la necesidad transitoria, sobresalga la caridad que permanece (1 Cor $12,21 ; 13,13) » 52$.

A ello hay que añadir el contenido del parágrafo siguiente:

52. «Ita sane, ut nullus sibi aliquid operetur, sed omnia opera uestra in commune fiant, maiore studio et frequentiori alacritate, quam si uobis singuli propria faceretis. Caritas enim, de qua scriptum est quod "non quaerat quae sua sunt" (1 Cor 13,5), sic intelligitur, quia communia propriis, non propria communibus anteponit. Et ideo, quanto amplius rem communem quam propria uestra curaueritis, tanto uos amplius profecisse noueritis; ut in omnibus quibus utitur transitura necessitas, superemineat ( 1 Cor 12,$31 ; 13,13$ ), quae permanet, caritas» ( $R$ $\mathrm{V}, 2)$. 
«De donde se sigue que, si alguien trajese a sus hijos o allegados que viven en la casa religiosa alguna cosa..., no se reciba ocultamente, sino que se entregue al superior para que, al hacerla común, se conceda a quien la hubiere menester» 53 .

Añádase todavía lo preceptuado en el primer parágrafo en el sentido de tener la ropa en un lugar común y bajo custodia común ${ }^{54}$.

El tercer elemento señalado era la envidia (inuidentia). Es cierto que en el capítulo quinto no se encuentra el término, pero no lo es menos que se halla la realidad 55 .

En todo caso, si de algo no se puede dudar, es de que en el capítulo quinto con su aversión a la propiedad privada y su promoción de lo común san Agustín trata de evitar el orgullo. El «amor privado» es lo que lo define. El orgullo se caracteriza precisamente por anteponer el bien particular al bien común 56 . Un par de textos de obras ajenas a las que nos vienen ocupando, pueden servir de ejemplo. El primero tiene la ventaja de partir del texto de 1 Cor 13,5, citado en la Regla (V,2):

«La caridad, que no busca su propio interés» (1 Cor 13,5), es decir, que no pone su gozo en la propia excelencia y, por tanto, con razón no se envanece, es contraria a esta enfermedad del orgullo. Hay, pues, dos amores de los cuales uno es santo, otro inmundo; uno social, otro privado; uno que se preocupa de la utilidad común para conseguir la compañía celestial (= Dios), otro que hasta el bien común hace revertir en objeto de potestad propia por afán arrogante de dominar...» 57.

El segundo muestra cómo la discordia entre hermanos procede del orgullo que lleva a cada uno a mirar sólo por su parte:

«Busquen la posesión que no puede dividirse y vivirán siempre en concordia. ¿Qué origina la discordia entre los hermanos? ¿Qué causa la alteración de la piedad? ¿A qué se debe que sea uno sólo el seno y no una sola el alma? A que

53. «Consequens ergo est ut etiam si quis suis filiis, uel aliqua necessitudine ad se pertinentibus, in monasterio constitutis, aliquid contulerit, uel aliquam uestem, siue quodlibet aliud inter necessaria deputandum, non occulte accipiatur, sed sit in potestate praepositi, ut, in re communi redactum, cui necessarium fuerit, praebeatur (Hech 4,35)» (R V,3).

54. «... in unum habete... sub communibus custodibus» (R VI,1).

55. A este respecto remitimos a lo indicado a propósito del $D V R$ en relación con este mismo capítulo. Cf. Estructura [II], en Estudio Agustiniano 33 [1998] pp. 36-37.

56. Cf. De libero arbitrio 2,19,53 PL 32,1269.

57. «Cui morbo (superbiae) contraria charitas non quaerit quae sua sunt, id est non privata excellentia laetatur: merito ergo et non inflatur (1 Cor 13,5.4). Hi duo amores, quorum alter sanctus est, alter inmundus; alter socialis, alter privatus; alter communi utilitati consulens propter supernam societatem, alter etiam rem communem in potestatem propriam redigens propter arrogantem dominationem...» (De genesi ad litteram 11,15,CSEL 28/1, 347-348). 
sus almas están inclinadas y cada uno mira por su parte (= orgullo) y se esfuerza por agrandarla y aumentarla, y quiere que sea únicamente suyo lo que posee, él que comparte lo de su hermano» 58 .

A propósito del deseo de alabanzas, aludía san Agustín al incomodo que le producían las afrentas que recibía (iniuste vituperetur; contumelia magis mordeor), aunque no cayese en la reacción normal de los hombres, esto es, la ira y el deseo de venganza (libido uindicandi), porque el Señor, al trasformarle, aunque parcialmente, ya le había librado de él. El capítulo de la Regla que se corresponde con este apartado es el sexto. La correspondencia es plena, siempre que se tenga en cuenta lo dicho anteriormente, acerca de los dos modos como la lengua ajena puede provocar el orgullo de una persona: a través de la alabanza o a través de la maledicencia. La Regla pasa por alto el primer caso, y se ocupa exclusivamente del segundo, esto es, de aquel en que un hermano ofenda a otro con injurias, ultrajes o reproches ${ }^{59}$, que suscitan la ira.

Por último, la primera manifestación del orgullo, señalada por san Agustín en $\mathrm{C} 10$, la pretensión de dominar sobre los demás, que se manifiesta en concreto en el deseo de la persona constituida en autoridad de ser amada y temida en sí y por sí misma. Quien conoce la Regla reconocerá de inmediato la presencia del primer elemento, el dominio, en su capítulo séptimo, donde se lee: «El que os preside, no se sienta feliz por dominar con poder, sino por servir con caridad» ${ }^{6}$. Reconocerá asimismo la presencia del segundo elemento: el deseo de ser amados y temidos, en estas otras: «Y aunque ambas cosas sean necesarias, busque más ser amado que temido» 61 . Advertirá, finalmente, el tercer elemento señalado, las repercusiones en el día del juicio, aunque con formulación diferente: «pensando que ha de dar cuenta a Dios por vosotros» 62 .

Pasando a esquema el resultado de los análisis anteriores, obtenemos el siguiente:

\section{Ambición mundana:}

C10: tomar los dones de Dios como propios / no gozar de ellos con los demás / envidia $(39,64)$

Regla: propio / común / (envidia) (V).

58. S. 359,2; Cf. S. 265,11; G. MADEC, Le communisme spirituel, en Homo religiosus, p. 232. 59. «quicumque conuicio, uel maledicto, uel etiam criminis obiectu, alterum laesit» (R VI,2).

60. «...non se existimet potestate dominantem, sed caritate seruientem felicem» (R VII,3). VII,3).

61. «Et quamuis utrumque sit necessarium, plus a uobis amari appetat quam timeri» (R

62. «...semper cogitans deo se pro uobis redditurus rationem» ( $\mathrm{R}$ VII,3). 
C10: afrenta / [ira] / deseo de venganza (36,58; 37,61-62)

Regla: injuria o ultraje / ira / (venganza) (VI)

C10.: afán de dominio / ser temido y amado / consecuencias para el día del juicio $(36,59)$

Regla: dominar con poder / busque más ser amado que temido / ha de dar cuenta a Dios por vosotros (VII,3) ${ }^{63}$.

La correspondencia nos parece indiscutible. A partir de aquí creemos que se puede dar por demostrado lo que fue punto de partida, a saber, que los capítulos quinto, sexto y séptimo forman una unidad estructural en el interior de la Regla con la tercera concupiscencia, la ambición mundana, como criterio unificador. Dicha unidad recibe también, en cuanto a extensión, un tratamiento amplio que se corresponde con el recibido en $\mathrm{C} 10$.

\subsubsection{Comparación entre las secciones $C$ de C10 y de la Regla}

Concluida la comparación entre la sección B de C10 y la de la Regla, es el momento de hacer lo mismo con la sección $\mathrm{C}$ de ambos escritos.

La sección C de C10 corresponde a los capítulos 42,67-43,69. El centro de la misma lo ocupa Jesucristo, en su función de mediador. Función que Agustín presenta en contraposición a la ejercida por los mediadores del paganismo. Mediadores falsos, pues no reunían las condiciones para serlo. En efecto, es necesario «que el mediador entre Dios y los hombres tenga algo en común con Dios y algo en común con los hombres. Pues, de asemejarse totalmente a los hombres, quedaría muy lejos de Dios, y de asemejarse totalmente a Dios, quedaría muy lejos de los hombres, y así no podría ser mediador» 64. Ahora bien, esas condiciones sólo las cumple el Señor Jesucristo. En

63. El mismo esquema en términos latinos:

Ambitio saeculi: 27,190)

C10: de bonis tuis quasi suis / non socialiter gaudentes / aliis inuidentes eam (39,64 CC

Regla: propria... / communial (inuidentia) ( $\mathrm{R}$ V).

C10: contumelia / [ira]/ libido uindicandi (36,58; 37,61-62 CC 27,186.188-189).

Regla: conuicio uel maledictum/ ira / (libido uindicandi) (R VI,2.1.2).

C10: (dominari) / timeri et amari uelle / iudicante te... damnante te $(36,59$ CC 27,187).

Regla: potestate dominantem / plus amari appetat quam timeri / pro uobis redditurum esse rationem ( $\mathrm{R}$ VII,3).

64. Conf. 10,42,67 CC 27,192. 
el punto siguiente muestra cómo, en efecto, realiza él esa función mediadora. Luego concluye:

«Mis razones tengo yo para abrigar una sólida esperanza de que sanarás todas mis dolencias (languores ${ }^{65}$ ) por medio de Él, que está sentado a tu derecha e intercede por nosotros ante ti (Rom 8,34). Si no fuera así, no me quedaría otro recurso que la desesperación. Mis dolencias (languores) son muchas y grandes... Pero más abundante es tu medicina. De no haberse hecho carne tu Palabra y habitado entre nosotros, con razón hubiéramos podido juzgarle apartado de la naturaleza humana y desesperar de nosotros» 66 .

Con el término dolencias (languores) alude a las heridas morales producidas en él por la triple concupiscencia, respecto de la cual acaba de examinar su conciencia, como resulta de un texto anterior 67. Frente a ellas, san Agustín presenta a Jesucristo como la medicina mediante la cual Dios le curará. De esta manera, Jesucristo aparece en relación, aunque sólo implícita y sin especificar, con las diversas concupiscencias.

¿Cabe esperar aquí algo positivo de la comparación entre y C10 y la Regla? Sin duda; pero sabiendo que convergencias y divergencias van de la mano. C10 y Regla convergen en establecer una relación de Cristo con las tres concupiscencias, y divergen en cuanto que la Regla establece una relación específica con cada una de ellas. Pero se trata de algo que hay que probar, pues no es de suyo evidente.

Recordemos el desglose que hicimos del texto en VIII, 1b, 1c y 1d ${ }^{68}$. El orden del análisis será $1 \mathrm{c}, 1 \mathrm{~b}$ y $1 \mathrm{~d}$. El resultado a que pretendemos llegar es la presencia, explícita o implícita, de Cristo en cada uno de los apartados.

\subsubsection{1. $R$ VIII,1c}

En nuestro planteamiento R VIII,1c es el correlativo en la sección C de la unidad segunda (la concupiscencia de la carne) de la sección B. Leemos: «inflamados por el buen olor de Cristo». Lo que propiamente nos importa es la mención explícita de Cristo, primera y última vez en todo el texto de la

65. Sobre languor, cf. I. BocheT, Saint Augustin et le desir de Dieu, Paris 1982, pp. 18-36.

66. «Merito mihi spes ualida in illo est, quod sanabis omnes languores meos per eum, qui sedet ad dexteram tuam et te interpellat pro nobis: alioquim desperarem. Multi sunt enim et magni; sed amplior est medicina tua. Potuimus putare uerbum tuum remotum esse a coniunctione hominis et desperare de nobis, nisi caro fieret et habitaret in nobis» (Conf. 10,43,69 CC 27,193).

67. En Conf. 10,41,66 escribe: «Por eso consideré mis dolencias (languores) pecaminosas bajo la triple forma de la concupiscencia». Texto latino en nota 117.

68. Cf. Estructura (I), en Estudio Agustiniano 32 (1997) 417-419. 
Regla, razón por la que hemos comenzado por este texto. Constatado el hecho, huelga todo comentario al respecto.

Pero, con referencia a la estructura global del documento, ha de advertirse otro particular: la referencia al único sentido ausente en la sección $\mathrm{B}$, el del olfato. ¿Por qué lo excluyó de allí? No lo sabemos, pero nada nos impide hacer conjeturas.

Quizá el santo prefirió silenciarlo en la sección B porque se trata de un sentido que no suele ser fuente de mayores desórdenes morales -al menos tal fue su propio caso ${ }^{69-}$ y optó por recuperarlo aquí, para mantener, a través de él, la realidad sensorial en esta nueva sección. En la sección B el legislador se había servido de cuatro sentidos para expresar el extravío del deseo que debía ser reorientado; en la $\mathrm{C}$, recurre al que falta, el del olfato, para expresar ese mismo deseo, ya rectificado, a través de 2 Cor 2,15 . Pero, entre una sección y otra, se ha dado un salto cualitativo. El olfato, al que aquí se hace referencia, no se refiere al sentido corporal; es ya un sentido interior, que tiene por objeto no ya los aromas sino a Dios mismo ${ }^{70}$.

Quizá también porque, de mantenerlo, se quebraba la armonía en la estructura. Sin duda, el sentido del olfato podía haberlo asociado sin violencia alguna tanto al sentido del gusto, como al del tacto, en cuanto que, por ejemplo, si el aroma de un plato bien cocinado estimula el apetito de comer, el perfume que desprende una persona puede estimular en otra el apetito sexual respecto de ella. Pero haberlo asociado a uno u a otro sentido, habría roto los equilibrios estructurales. Además, con la solución dada le mantiene el puesto central que le reserva en $\mathrm{C} 10$, creando una nueva estructura armónica:

Sección B Sección C

a) 2 (gusto, oído)

b) 1 (olfato)

c) 2 (tacto, vista).

69. Cf. Conf. 10,32,48 CC 27,180-181.

70. Cabría entenderlo desde Conf. 10,6,8 donde san Agustín contrapone los sentidos exteriores a los interiores y donde muestra a Dios satisfaciendo, al nivel de máxima plenitud, todos los sentidos del hombre interior: «Quid autem amo, cum te amo?... non candorem lucis ecce istis amicum oculis, non dulces melodias cantilenarum omnimodarum, non florum et unguentorum et aromatum suauiolentiam, non manna et mella, non membra acceptabilia carnis amplexibus: non haec amo, cum amo deum meum. Et tamen amo quandam lucem et quandam uocem et quendam odorem et quendam cibum et quendam amplexum, cum amo deum meum, lucem, uocem, odorem, cibum, amplexum interioris hominis mei, ubi fulget animae meae, quod non capit locus, et ubi sonat, quod non rapit tempus, et ubi olet, quod non spargit flatus, et ubi sapit, quod non minuit edacitas, et ubi haeret, quod non diuellit satietas» $(10,6,8$ CC 27,159). Cf. también Conf. 10,27,38 CC 27,176-277. 
Como ya indicamos, a) recoge los dos sentidos que en C10 ocupan la posición mediana (ni los más materiales, ni los más «espirituales»), y c) los dos sentidos de los extremos (el más material y el más «espiritual»).

Traigamos ahora a la memoria que, en el lugar correlativo al que nos ocupa, el DVR 53,103 71, Agustín recurría a Sal 33,9: «Y así gustarán cuán suave es el Señor». DVR y Regla coinciden en recurrir a un texto que expresa una sensación placentera del Señor para referirse a ese momento de la evolución moral de las personas, y divergen en la naturaleza de la sensación. La primera percibe el sabor, la segunda, el olor. El texto de 2 Cor 2,15 elegido por el santo en la Regla tiene algunas ventajas sobre Sal 33,9. La primera, introducir el sentido del olfato, excluido con anterioridad; la segunda, la mención explícita de Cristo, dándole entrada en el documento legislativo a través de una cita bíblica.

\subsubsection{2. $R$ VIII, $1 b$}

Recordemos su tenor literal: «como enamorados de la belleza espiritual». La cuestión que se plantea es: ¿qué debe entenderse bajo la expresión «belleza espiritual»? L. Verheijen, quien, como ya indicamos, dedicó tres artículos a estudiar el tema de la belleza espiritual en san Agustín, no ha mantenido siempre la misma respuesta. Con cautela ciertamente, en un primer momento remitía a Jesucristo. A propósito de la expresión flagrantes desiderio eius (es decir, de Jesucristo), presente en S. 210,3,4, escribe:

«Este texto nos hace comprender que la "belleza espiritual" de que habla la Regla es, o podría ser, la del Señor Jesús, resucitado tras su muerte, y elevado a la gloria celeste. Por otra parte hay que señalar que el nombre de Cristo aparece en la misma frase de la Regla» 72.

Un poco más adelante, continúa:

«"Como amantes de la belleza espiritual, difundiendo por vuestra santa vida el buen olor de Cristo...". Todo esto que precede parece autorizarnos a parafrasear: como amantes del esposo celeste, sustraído de aquí, pero que nos espera

71. Véase el esquema presente en Estructura [II], en Estudio Agustiniano 33 [1998] p. 49.

72. Les sermons de saint Augustin pour la carême (205-211) et sa motivation de la vie «ascetique», en Augustiniana 21 (1971) 357-404; esp. p. 396; NA I,192. Cf. también, Vers la beauté spirituelle..., p: 507; NA 1,239. 
allá; comportándonos como verdaderos amigos de este esposo, manteniendo el luto por un momento como consecuencia de su partida, pero totalmente llenos de un deseo ardiente de volver a verle...» ${ }^{73}$.

Una década más tarde, sin abandonar la prudencia a la hora de expresarse, cambia de opinión. Primero señala las clases de belleza en que teóricamente puede estar pensando san Agustín. Cuando él habla de belleza -afirma-, piensa tanto en la belleza de la naturaleza y de toda clase de fenómenos físicos, como en la Belleza de Dios que está en el origen del mundo. Pero a la Belleza de Dios remite también la belleza del mundo espiritual, la de la Iglesia, la del comportamiento y la de la vida interior de los hombres; por último señala que, hablando de la belleza de Dios, san Agustín no olvida que la vida divina es trinitaria. $\mathrm{Y}$ añade:

«Pero el capítulo VIII,1 del Praeceptum, pasaje cuya importancia en la estructura del conjunto del documento hemos acentuado, nos ayuda a limitar nuestro propósito. Después de haber dicho: "... como amantes de la belleza espiritual", este capítulo continúa: "difundiendo por vuestra conducta el buen olor de Cristo". Parece, pues, que san Agustín, al evocar la belleza espiritual, ha pensado más particularmente en la belleza del "alma" del comportamiento de los monjes a los que se dirigía» ${ }^{74}$.

Él mismo sintetiza su artículo sobre la comprensión de la belleza espiritual por parte del obispo Agustín. Lo hace con estas palabras:

«El punto de partida de nuestra primera investigación se halla en la conclusión de la Regla de san Agustín. El autor echa una mirada atrás, una mirada englobante y profundizadora, bajo la forma de una oración. Exhorta a sus monjes a observar los preceptos dados en el cuerpo de la Regla, y esto con amor, como amantes de la belleza espiritual, y difundiendo por su comportamiento el buen olor de Cristo... San Agustín, en dicho texto, piensa, pues, no en la belleza en general, sino más específicamente en la del buen comportamiento humano. Es esta la razón por la que, en nuestro anterior artículo, hemos centrado nuestra atención sobre los textos del obispo Agustín que hablan precisamente de esta belleza» 75 .

73. Ib. p. 397; NA I,192.

74. Comme des amants... Dans Augustin evêque..., p. 93-94; NA II, 122-123.

75. Comme des amants de la beauté spirituelle. Dans les oeuvres du jeune Augustin, en Augustiniana 33 (1983) 86-111, esp. p. 103; NA II, 211. Esa belleza se concreta en las virtudes: «La belleza espiritual... ¿Cómo hay que comprender estas palabras en función de los textos de san Agustín en el período episcopal?... Para san Agustín obispo son las virtudes las que pro- 
En cuanto a los demás autores, hay divergencias. Según A. Manrique, al hablar de la belleza espiritual, el santo piensa en la unidad y en la eternidad; en Dios en definitiva ${ }^{76}$. A. Sage tiene en mente la belleza de Jesucristo ${ }^{77}$. A. Trapè identifica la belleza espiritual con la belleza de la Sabiduría, la belleza de Dios ${ }^{78}$. T. van Bavel habla de la belleza máxima, la belleza divina ${ }^{79}$. Sor Maria-Ancilla piensa en las virtudes ${ }^{80}$. Según Sister Agatha Mary belleza para san Agustín expresa la condición por la que el Unico a quien él estaba buscando es plenamente atractivo y amable 81 . A. De Vogüé, por su parte, apunta a la posibilidad de que la «belleza espiritual» se refiera a toda belleza 82 .

Personalmente nos sentimos más cercanos de la primera interpretación de L. Verheijen que de la segunda. Estamos persuadidos de que, en la Regla, «Belleza espiritual» es como un «nombre» de Cristo ${ }^{83}$. Con otras palabras, que san Agustín presenta a los siervos de Dios como enamorados de la persona de Jesucristo. Varias son las razones que, a nuestro parecer, avalan esta posición.

En primer lugar, la lógica de todo el planteamiento que venimos haciendo. En la medida en que la sección B de la Regla tiene como trasfondo el deseo «pervertido» y en la sección $\mathrm{C}$ el deseo reorientado, este deseo sólo Dios lo puede plenificar y, para convencerse de ello, basta con releer el texto de Conf.

ducen la belleza del alma humana, la fides -fe y fidelidad-, la sabiduría, la castidad, la justicia (que en el fondo no es otra cosa que la caridad), la caridad misma: la caridad es la belleza del alma. Pero la belleza espiritual no está limitada a las almas individuales de unos y otros. Su conjunto, la Iglesia, tiene también su belleza: su unidad. Por otra parte, existe una relación precisa entre la caridad en el corazón de cada uno y la unidad de la Iglesia en su conjunto. Todo es bello en este gran espectáculo» (Comme des amants... Dans Augustin evêque..., p. 135; NA II, 164; los subrayados son del autor mismo).

76. Teología agustiniana de la vida religiosa, p. 341.

77. «... como religiosos enamorados de la belleza que se refleja en el rostro de nuestro divino esposo. Desde el cielo, donde todo es armonía y esplendor, acude hasta nosotros con el resplandor de su belleza de Hijo de Dios» (La Regla, p. 132). 219).

78. La Regola, p. 215. Aunque no olvida hablar también de la belleza de Cristo (ib. p. 218-

79. Regla para la comunidad, p. 95.

80. La Règle de saint Augustin, p. 150.

81. The Rule of Saint Augustin. An Essay in Understanding, Augustinian Press, Villanova 1992, p. 332: «beauty for him expressed the utter desiderability and the utter loveliness of the One whom he was seeking».

82. «De son côté, la Règle prend des grandes proportions, quando on demande au Seigneur le don de l'observer par amour, en vue de la beauté spirituelle. En écrivant ces mots, Augustin peut se souvenir d'un de ses premières écrits, le $D e$ ordine, où il donnait le titre $\mathrm{d}^{\prime}$ "amant de toute spèce de beauté" a son ami Zenobius $(1,4)$ " (Histoire littéraire..., III, 202). poseía.

83. Lo cual no quita que deba su belleza también a las virtudes que, en cuanto hombre, 
1,20,31 84; más en concreto, Jesucristo, como tendremos ocasión de ver ${ }^{85}$. Pero no olvidamos que la veracidad de tal planteamiento es lo que tratamos de demostrar, y apoyarnos en él equivaldría a caer en una petitio principii.

Más peso puede tener la comparación con DVR. A quienes se sienten atraídos por la belleza de los espectáculos exteriores, en dicha obra el santo les invita a preferir la belleza de la Sabiduría creadora que, obviamente, remite a la persona de Jesucristo ${ }^{86}$. Por el argumento a pari y, habida cuenta de los paralelismos antes detectados entre ambos escritos, no parece descabellado, pues, pensar que acontezca lo mismo en la Regla. Esto es, que a los «espectáculos», exteriores o interiores, que interrumpen o perturban la oración, oponga también la contemplación de la persona de Jesucristo, presentada como dechado de belleza espiritual.

La comparación con los sermones de cuaresma conduce a la misma conclusión. Al respecto no es preciso detenernos porque ha sido el mismo L. Verheijen quien lo ha estudiado, llegando a la conclusión ya expuesta 87.

La lógica de un planteamiento que, al menos, es posible aceptar como respondiendo a la realidad y la comparación con otros textos, paralelos en mayor o menor grado a la Regla, nos lleva a la conclusión de que la Belleza espiritual del capítulo VIII,1 se identifica con Jesucristo. Esta conclusión, sin embargo, necesita ser apuntalada aún con dos argumentos, de carácter positivo y teológico el primero, y negativo y filológico el segundo.

La belleza de Cristo es tema frecuente en el período episcopal de san Agustín. En su estudio sobre la spiritalis pulchritudo en las obras de dicho período L. Verheijen comienza por el examen de Tractatus in Ioannis epistulam ad Parthos 9,9. Dicho texto orienta su investigación, porque constituye una buena síntesis del pensamiento del santo al respecto, necesitando sólo pocos complementos. Pues bien, tras algunas consideraciones sobre la relación entre amor y belleza, $1 \mathrm{Jn}$ 4,9 le introduce en la consideración de la belleza de Cristo, combinando tres pasajes bíblicos: Sal 44,3, Is 53,2-3 y Flp 2,6-8. Se podría objetar que el texto es posterior en varios años 88 a la supuesta fecha

84. Traigo aquí la parte que procede: «En lo que pecaba yo entonces era en buscar en mí mismo y en las demás criaturas, no en Dios, los deleites, grandezas y verdades, por lo que caía luego en dolores, confusiones y errores». Más amplio en Estructura [I], en Estudio Agustiniano 32 (1997) p. 422.

85. Cf. Conf. 9,1,1 CC 27,133.

86. DVR 52,101. Cf. Estructura [II], en Estudio Agustiniano 33 (1998) p. 40.

87. Cf. antes, notas $72-73$.

88. Los Tractatus in Ioannis epistulam fueron predicados en la semana de Pascua del 407. Cf. A.M. LA BonNARDIÈre, Recherches de chronologie augustinienne, Paris 1965; M.-F. BE- 
de composición de la Regla, el 397, igual que la mayoría de los textos examinados en el artículo. Pero pueden entenderse como el afianzamiento de una idea que se formó en su mente mucho antes. De hecho aparece ya antes en De sancta virginitate, cuya fecha tradicional de composición ha sido puesta en tela de juicio por algún autor, que la hace coincidir con la de las Confesiones ${ }^{89}$. En esta obra san Agustín invita a las vírgenes a contemplar la belleza de Cristo en estos términos:

«Si, pues, habéis rechazado el matrimonio humano... amad con todo el corazón al más hermoso de los hijos de los hombres; estáis libres, tenéis el corazón libre de los lazos conyugales. Contemplad la belleza de quien os ama, miradle igual al Padre y sumiso a la voluntad de la madre; imperando en los cielos y viniendo a servir en la tierra; creando todas las cosas y siendo creado entre ellas Ved cuán bello es aquello que en él es motivo de guasa para los soberbios; con la luz interior de vuestra alma mirad las heridas del crucificado, las cicatricès del resucitado, la sangre del que muere, el precio de quien cree, el comercio del redentor» 90.

El adjetivo «espiritual» no aparece aquí para calificar la belleza de Cristo, pero se sobreentiende. Es evidente respecto de la belleza que resulta de su condición divina, por la que es igual al Padre. Pero sólo pensando en la belleza espiritual puede hablarse de ella respecto a su condición humana. A nivel físico, la realidad mostraba precisamente lo contrario. San Agustín se complace en señalar el contraste entre lo que era motivo de guasa para los sober-

RROUARD, Date des Tractatus in Ioannis Evangelium de saint Augustin, en Recherches Augustiniennes 7 (1971) 105-168.

89. Nos referimos a M.-F. Berrouard quien escribe: «En raison de la place qu'il occupe en Retr. 2,22, les auteurs s'accordent pratiquemente à dater le de bono coni. (y por extensión del De s. virg.) de 401. Mais cette date me paraît si tardive qu'elle rend incompréhensible l'intervention d'Aug., à moins d'imaginer qu'il n'a appris qu'alors l'affaire qui agitait les milieux romains sept à huit ans auparavant. Je me demande... s'il ne faudrait pas en conséquence avancer des qualques années, jusque vers 397, la date traditionelle du b. coni.» (Bono coniugali (De-), en Augustinus Lexikon I, 659. Por el contrario, F. Dolbeau propone retrasar su composición hasta el 404-405 (cf. Nouveaux sermons d'Augustin, IV, en Recherches Augustiniennes 26 (1992) p. 83, n. 86; Vingt-six sermons..., p. 359).

90. De sancta virginitate 54,55 CSEL 41,300: «Si ergo nuptias contempsistis filiorum hominum... toto corde amate speciosum forma prae filiis hominum: vacat vobis, liberum est cor a coniugalibus vinculis. Inspicite pulchritudinem amatoris vestri: cogitate aequalem Patri, subditum et matri; etiam in caelis dominantem, et in terris servientem; creantem omnia, creatum inter omnia. Illud ipsum, quod in eo derident superbi, inspicite quam pulchrum sit; internis luminibus inspicite vulnera pendentis, cicatrices resurgentis, sanguinem morientis, pretium credentis, commercium redimentis». El contexto es aquí ligeramente distinto, pero sólo nos interesa poner de relieve la belleza de Cristo, belleza que va asociada tanto a su condición divina como a la humana. 
bios (judíos), su condición de crucificado deforme, y la belleza que, no obstante, reflejaba. Pero belleza moral, la belleza de su amor que dejan traslucir sus heridas 91 . Belleza espiritual, porque sólo se puede contemplar «con la luz interior» del alma.

El texto de De sancta virginitate, que pudiera ser contemporáneo de la Regla, explica a la perfección la frase de la Regla: no sólo refiere a Cristo la belleza, una belleza espiritual, sin duda, sino que, además, lo hace dirigiéndose a personas de uno y otro sexo que han consagrado a Dios su virginidad.

El otro argumento -decíamos- tiene carácter negativo y filológico. Negativo en cuanto pretende anular la base de la interpretación que consideramos errónea. En efecto, la segunda interpretación de L. Verheijen se sustenta sobre una determinada traducción de flagrantes. El sabio agustino vierte al francés la frase en estos términos: "répandant" la bonne odeur du Christ», dándole un sentido activo. Hay que añadir que es la traducción habitual. De las que hemos podido tener en mano solamente dos, la recogida en la última edición española de la Regla y Constituciones de la Orden de san Agustín y la de la traducción de la Regla en la edición española de las obras Completas de san Agustín, ofrecen una traducción diferente: «... e inflamados por el buen (o suave) olor de Cristo» ${ }^{92}$. En nuestra opinión, esta traducción se ajusta más a la realidad. En primer lugar, ninguno de los diccionarios latinos que hemos podido consultar ${ }^{93}$, incluye el significado de difundir, expandir, para el verbo flagro. Todos sus significados se mueven dentro del campo semántico del fuego, de la llama. Además, parece reclamarlo el contexto: amatores, flagrantes parecen tener valor de sinónimos, en cuanto que indican ambos la actitud psicológica dentro de la cual es posible cumplir lo preceptuado anteriormente ${ }^{94}$. Más aún, cabe pensar que el amatores y el flagrantes no hacen

91. A propósito de este texto, escribe L. Verheijen: «Para comprender este texto, hay que leerlo a la luz de los comentarios agustinianos a Sal 44,3-Jesucristo es el más bello entre los hijos de los hombres, porque sólo Él, entre ellos, es la Palabra del Padre- y a la luz de la doble explicación de Is 53,2 -en cuanto hombre, sobre todo en cuanto hombre crucificado, carecía de belleza y resplandor-; pero a los ojos de los creyentes él es divinamente bello hasta, $o$ incluso, en su anonadamiento. Estos dos pasajes bíblicos, junto con Fil 2,6-7, sin haber sido citados, sostienen este bello texto" (Comme des amants de la beauté spirituelle. Dans Augustin évêque, p. 143; NA II, 163).

92. Regla y Constituciones de los hermanos de la Orden de san Agustín, Madrid 1991, p. 45; Biblioteca de Autores Cristianos, vol. 551, Madrid 1995, p. 590. La traducción es de T. C. Madrid.

93. Entre ellos el Thesaurus linguae latinae, VI,846-848.

94. A. Sage considera el amor de la belleza espiritual ( $R$ VIII,1b), el exhalar un perfume divino (VIII,1c) y la libertad de corazón (VIII,1d) como señales del cumplimiento de la Regla 
sino especificar el cum dilectione anterior. Por último, esta traducción encaja sin dificultad en la estructura y lógica que venimos proponiendo para la Regla: el siervo de Dios que, fiel a lo ordenado en la sección $\mathrm{B}$, renuncia a algo aparece en la sección $\mathrm{C}$ ardiendo en deseos de aquello mismo a lo que había renunciado, aunque en un nivel superior. En concreto, si conforme a la unidad segunda de la sección $\mathrm{B}$ ha renunciado a toda satisfacción innecesaria de los sentidos, ahora en la $\mathrm{C}$ se encuentra anhelando la satisfacción de los sentidos interiores, representados en el del olfato ${ }^{95}$. Cosa distinta es en qué consista específicamente ese «buen olor de Cristo» del que pensamos ocuparnos en otro momento.

\subsubsection{3. $R$ VIII,1d}

Por último, ¿qué decir a propósito de VIII,1d: No como siervos bajo la ley, sino como personas libres bajo la gracia? ${ }^{96}$. Aunque Jesucristo no es mencionado explícitamente, se puede intuir su presencia tras el concepto clave de la libertad. Ningún cristiano ignora que a él debe la libertad evangélica. No obstante, no debemos conformarnos con deducciones teológicas. Es preciso considerar más de cerca el texto mismo.

En su tenor literal ni sicut serui sub lege, ni sicut liberi sub gratia constituti pertenecen al texto bíblico, ni son atestiguados como variantes por las ediciones críticas de la Biblia griega, ni mencionadas en el fichero del Instituto de la Vetus Latina ${ }^{97}$. El texto más cercano lo encontramos en Rom 6,14: non enim sub lege estis, sed sub gratia (Pues no estáis bajo la ley, sino bajọ la gracia) 98 . No cabe duda de que san Agustín no cita literalmente; las palabras de la Regla resumen un pasaje paulino más o menos largo. ¿De cuál se trata? Apoyándose, sin duda, en la indiscutible cercanía al texto señalado de Rom 6,14, L. Verheijen, remite en su edición crítica a Rom 6,14-22, referencia que es recogida, sin mayor reflexión, por las ediciones posteriores que hemos consultado.

Aunque posible, no nos parece probable. La frase non sicut serui sub lege, sed sicut liberi sub gratia constituti que -repetimos- no es cita textual, puede

(La Regla, p. 132). En nuestra opinión, en esta sección del documento san Agustín, más que señales del cumplimiento, indica las condiciones que lo hacen posible.

95. Cf. antes nota 70 .

96. «... non sicut servi sub lege, sed sicut liberi sub gratia constituti».

97. Cf. T. VAN BAVEL, "Ante omnia» et «in deum» dans la "Regula sancti Augustini», en Vigiliae Christianae 12 (1958) 157-165; en concreto, p. 164.

98. Tal es la versión del texto que el mismo san Agustín da en Expositio quorumdam propositionum ex epistula ad romanos 35: PL 35,2069. 
condensar con al menos igual probabilidad otro pasaje paulino. Si se consideran de cerca los dos textos, se advierte que el de la Regla juega con la contraposición entre dos situaciones del hombre: servidumbre y libertad con referencia a la ley y a la gracia. Ahora bien, en Rom 6,14-22 la libertad es mencionada, pero no aparece como el término privilegiado para designar la situación positiva en que se halla el cristiano. Hasta la nueva situación es presentada sobre todo en términos de servidumbre. La diferencia entre la situación que precede y la que sigue a la integración en Cristo se diferencia sólo por el «señor» a que se sirve: o el pecado, antes, o la justicia, después. Lo dicho se puede percibir mejor en el siguiente cuadro:

Os hacéis esclavos (serui estis)

bien del pecado, para la muerte,

bien de la obediencia, para la justicia (v.16)

Liberados (liberati) del pecado, os habéis hecho esclavos (serui) de la justicia (v. 18)

Como en otros tiempos ofrecisteis vuestros miembros...

como esclavos (seruire) de la impureza para la maldad, ofrecedlos ahora

como esclavos (seruire) de la justicia para la santificación (v. 19)

Cuando erais esclavos (serui) del pecado, erais libres (liberi) respecto de la justicia (v. 20).

Como se ve, la libertad sólo es mencionada dos veces: en un caso los destinatarios de la carta aparecen como liberados del pecado, en otro como liberados de la justicia, aspecto este último que no tiene nada de positivo. Además, la situación positiva es presentada sobre todo como una servidumbre: a la obediencia (v. 16) y a la justicia (vv. 18 y 19). Estamos lejos, por tanto, de la formulación de la Regla.

Entonces, ¿qué otro pasaje paulino puede compendiar san Agustín en R VIII,1d? En nuestra opinión, Rom 7,5-8,4. Basta recorrer los textos agustinianos anteriores al 397 en que el Santo se sirve del binomio sub lege, sub gratia y advertir a qué pasajes del Apóstol remite. El trabajo de individuarlos ya lo hizo L. Verheijen, en un artículo en que tomó precisamente R. VIII,1d como criterio para discernir entre dos fechas propuestas para la composición de la Regla ${ }^{99}$.

99. Nos estamos refiriendo al artículo ya citado: La Loi et la grâce. La «date ancienne» et la «date récente» du Praeceptum... 
Para entender los datos que vamos a aportar es preciso traer a la memoria que san Agustín divide la historia del pueblo de Dios en cuatro períodos denominados, respectivamente, ante legem, sub lege, sub gratia, in pace ${ }^{100}$. En la primera etapa, el hombre pecaba, pero, al carecer de la ley (ante legem), no era consciente de ello. En la segunda, el hombre ya conoce la ley (sub lege) y siente deseos de cumplirla, pero otras fuerzas tiran de él en dirección contraria y acaba vencido por el pecado, a no ser que invoque la gracia de Dios. En la tercera etapa, el hombre sigue sintiendo en su interior esas fuerzas adversas, pero en virtud de la gracia que le aporta Cristo recupera la libertad frente a ellas (sub gratia). La cuarta y última etapa es aquella en que el hombre ya ni sentirá tales fuerzas adversas, por lo que no necesitará ni luchar. En ese momento habrá alcanzado la paz plena (in pace).

Pasemos revista ahora a los textos seleccionados por L. Verheijen en los que aparece claramente el binomio sub lege, sub gratia.

Comenzamos por la obra Expositio quorumdam propositionum ex epistula ad Romanos. Un primer texto es significativo porque expone Rom 6,14. En la expresión non estis sub lege, sed sub gratia ve descrita la tercera etapa antes señalada, etapa que hace coincidir con la situación expuesta en Rom 7,25 b ( $«$ Soy yo mismo quien con el espíritu sirve a la ley de Dios, mas con la carne, a la ley del pecado») ${ }^{101}$. En un segundo texto, el binomio aparece a propósito precisamente del comentario a Rom 7,23-25. El sub lege lo hace coincidir con Rom 7,23-25a ( «Pero advierto otra ley en mis miembros que lucha contra la ley de mi espíritu y me esclaviza a la ley del pecado, que está en mis miembros. ¡Infeliz de mí! ¿Quién me librará de este cuerpo de muerte? La gracia de Dios por nuestro señor Jesucristo») y el sub gratia, de nuevo con Rom 7,25b 102. En un tercer pasaje todavía, comenta Rom 8,1 que refiere a la tercera etapa, el sub gratia, que una vez más identifica con Rom 7,25b ${ }^{103}$.

La Epistulae ad galatas expositio ofrece un panorama similar. En un pasaje en que describe las cuatro etapas, al exponer la tercera, la sub gratia, remite de nuevo a Rom 7,25b ${ }^{104}$, si bien junto con Rom 6,12 105 . A continuación, a propósito de Ga 5,18, vuelve a recurrir a Rom 7,23 para describir la etapa sub lege ${ }^{106}$.

100. Cf. Expositio quorumdam propositionum ex epistula ad Romanos 13-18; De diversis quaestionibus LXXXIII, 61,7; 66,3ss; Epistulae ad galatas expositio, 46.

101. Expositio quorumdam propositionum ex epistula ad Romanos, 35.

102. Ib. $45-46$.

103. Ib. 47.

104. Epistulae ad galatas expositio, 46.

105. $\mathrm{Ib}$.

106. Ib. 47. 
En la obra De diversis quaestionibus $L X X X I I I$ vuelve sobre la división de la historia de Israel en las cuatro etapas. Al hablar, de forma general, de la tercera, sub gratia, la presenta como la correspondiente al momento en que ya creemos plenissime a nuestro Liberador, término en que hay que ver una referencia a Rom 7,25 107. Un poco después se ocupa detenidamente de la etapa segunda, sub lege; para describirla, además de Rom 5,20, recurre a Rom 7,5-25a. Para presentar la tercera etapa, la sub gratia constituti, se sirve de un texto esta vez más amplio: Rom 7,25b-8,4 108 .

Por último, la obra $D e$ diversis quaestionibus ad Simplicianum. Ya en el primer capítulo se ocupa por dos veces de la etapa sub lege, explicándola en ambos casos a partir de Rom 7,14 109 .

Todo lo anterior permite sacar esta conclusión: R VIII,1d compendia, no Rom 6,14-22, sino Rom 7,5-25, aunque en algún texto lo alargue a los primeros versillos de Rom 8. Una prueba ulterior nos la brinda el DVR. En su momento quedó establecido el neto paralelismo entre la Regla y dicha obra. Justamente al que vence la cupiditas excellentiae o tercera concupiscencia y reorienta su deseo pervertido, san Agustín le garantizaba, para la vida futura, eso sí, la libertad, y aducía también como apoyo bíblico Rom 7,23-25. Dicho de otro modo, en DVR el santo servía con todas las palabras lo que en R VIII,1d presenta oculto en la frase «no como siervos bajo la ley, sino como personas libres bajo la gracia».

Todo el capítulo séptimo de la carta a los Romanos está centrado en la ley, lo que da razón del sub lege; pero, en un final estratégico, aparece la gracia que aporta Jesucristo que libera al hombre de la esclavitud a la ley del pecado y le introduce en la etapa siguiente, sub gratia. En el contexto de Rom 7, se explica mejor que en el de Rom 6, 14-22 el serui sub lege, e igualmente el sub gratia constituti, un participio pasivo que señala que no se trata de una acción del hombre, sino de una pasión, es decir, de la aceptación del don de Dios por medio de Jesucristo. Jesucristo, pues, está muy presente también en R VIII,1d. No está su nombre, pero sí su obra; sin Él no sería posible el superar la esclavitud de la ley y ponerse al amparo de la gracia.

La mención de la ley nos lleva a preguntarnos de qué ley se trata. Es evidente que no se trata de los preceptos legales del Antiguo Testamento, sino de la ley del pecado (Rom 7,23). Esta consiste en el hecho de que, a consenada.

107. De diversis quaestionibus $L X X X I I I, 66,3$. O también Rom 8,2 , lo cual no cambia 108. $I b .66,5-6$.

109. De diversis quaestionibus ad Simplicianum 1,1,1.7. 
cuencia del pecado, todo hombre debe morir (¿Quién me librará de este cuerpo de muerte?), no obstante que su deseo más profundo sea el de vivir. De ahí que se agarre a poseer cosas que le posibiliten dicha vida; detrás de la avaricia está, en efecto, el temor a la muerte ${ }^{110}$. De ahí también que mire a los demás como competidores en esa lucha por la vida, de donde surge el deseo de imponerse y dominar sobre ellos y la falta de paz no sólo en el interior de cada hombre sino también en las relaciones sociales 111. Tal es el contenido de los capítulos quinto, sexto y séptimo, esto es, de la unidad tercera de la sección B de la Regla, a la que corresponde R VIII,1d en la sección C.

En conclusión, aunque el nombre de Cristo sólo aparezca explícitamente mencionado en R VIII,1c, está igualmente sobreentendido tanto en R VIII, $1 \mathrm{~b}$ como en $\mathrm{R}$ VIII,1d.

Presentado en esquema lo dicho a propósito de la sección C de C10 y de la Regla, resulta lo siguiente:

C10: Cristo, medicamento que cura las dolencias del hombre

Regla:

Concupiscencia de los ojos: Belleza espiritual (de Cristo).

Concupiscencia de la carne: Buen olor de Cristo.

Ambición mundana: Gracia liberadora, traída por Cristo 112.

Cabe preguntarse ahora cómo cura Jesucristo las dolencias que originan cada una de las concupiscencias. En C10 no formula respuesta alguna concreta, aunque pudiera deducirse de cuanto escribe a propósito de cada una de ellas. Pero la podemos extraer de la Regla. Jesucristo cura las dolencias producidas por la concupiscencia de los ojos, presentándose como la belleza espiritual, alternativa a la física y exterior que busca ella; cura las producidas por

110. «Ex ipsius enim mortalitate indigentia rerum terrenarum sollicitat animam, et quaedam desideria excitat, quibus ad peccandum non obtemperat qui iam mente servit Legi Dei» (Expositio quorumdam propositionum, 50 PL 35,2073; cf. también, 52-53). La venida de Cristo ofreció el remedio: «id enim egit mors Domini, ne mors timeretur, et ex eo iam non appeterentur temporalia bona, nec metuerentur temporalia mala, in quibus carnalis erat illa prudentia, in qua impleri legis praecepta non poterant» (Ib. 48 PL 35,2072).

111. La pérdida de la paz a consecuencia del pecado, es idea frecuentemente repetida por Agustín en el período del sacerdocio, siempre vinculada a Rom 7,23-25. Cf. De sermone Domini in monte 1,12,36; 2,6,23; 2,11,38; Expositio quorumdam propositionum, 13-18.

112. El mismo esquema en sus términos latinos:

C10: Christus, per quem sanabis languores (ex ea ortis).

Regla:

Concupiscentia oculorum: Spiritalis pulchritudo (Christus).

Concupiscentia carnis: Et bono Christi odore.

Ambitio saeculi: Liberi sub gratia (per Christum). 
la concupiscencia de la carne, presentándose como el objeto que satisface los sentidos interiores (aquí representados por el del olfato), que otorgan una felicidad más auténtica y plena que la satisfacción de los sentidos corpóreos; cura de las producidas por la ambición mundana, presentándose como quien, en virtud de su resurrección, libera del cuerpo mortal, es decir, de la muerte, por lo que el hombre ya no necesita supeditarse a los bienes temporales ni imponerse sobre los demás, llevado por la necesidad de sobrevivir, y merced a su envío del Espíritu santo, portador de la caridad.

En definitiva, aunque aquí los resultados no hayan sido siempre tan evidentes como respecto de la sección anterior, hay una coincidencia de fondo, creemos, entre C10 y Regla a propósito de la sección C de cada uno de los escritos.

\subsubsection{El epílogo}

En este mismo contexto, es preciso dirigir la mirada también al último parágrafo de $\mathrm{C} 10$, al que asignamos el valor de epílogo que contiene una confesión y una decisión personal. La confesión: la tentación de huir a la soledad; la decisión, el rechazo de la misma. Tal rechazo tiene un fundamento cristológico: Por eso murió Cristo: para que los que viven ya no vivan para sí, sino para aquel que murió por ellos (2 Cor 5,15). Pero lo que mayormente nos importa del texto es la continuación, en que narra sus tres languores: dos de ellos guardan relación consigo mismo: el primero, su ignorancia, que reclama un maestro; el segundo, su debilidad, que pide un médico; el tercero, guarda relación con otras personas: los soberbios que le calumnian 113. También aquí podemos descubrir la referencia a las tres unidades que constituyen la sección B y C de la Regla: la ignorancia remite a la unidad primera; la debilidad, a la unidad segunda; las relaciones con los demás, a la unidad tercera ${ }^{114}$.

\subsubsection{Conclusiones}

El resultado global de la comparación entre los dos documentos agustinianos queda reflejado en el siguiente cuadro:

113. «... Ideo Christus pro omnibus mortuus est, ut qui vivunt iam non sibi vivant, sed ei qui pro ipsis mortuus est $(2$ Cor 5,15)... Tu scis imperitiam meam et infirmitatem meam: doce me et sana me... Non calumnientur mihi superbi (Psal 118,122)... » (10,43,70 CC 27,193).

114. Este esquema estructura la Enarratio in psalmum 37 en que, como veremos en su momento, se adivina también una estructura similar a la de la Regla. 
COMPARACIÓN ENTRE LA REGLA Y C10

Sección A

\begin{tabular}{|l|}
\hline Hacia Dios \\
Hacia tu paz \\
Unánimes y concordes \\
un alma \\
yun solo corazón \\
El espiritu fraterno \\
que se une en acción \\
de gracias y súplica \\
de perdón \\
\\
Honrad a Dios los \\
unos en los otros \\
Turibulos, fragancia \\
de tu santo templo
\end{tabular}

Sección B

\begin{tabular}{|c|c|c|}
\hline$\dot{. j}$ & $\mid$ & $\begin{array}{l}\text { a) Quién piense hacer algo en el oratorio, } \\
\text { no impida la oración. } \\
\text { b) Sienta el corazón lo que pronuncia la voz. } \\
\text { a) "espectáculos menores" que interrumpen } \\
\text { la oración. } \\
\text { b) "espectáculos interiores" que turban } \\
\text { la oración. }\end{array}$ \\
\hline 总 & Fi & $\begin{array}{l}\text { a) (gusto): comida y bebida. } \\
\text { b) (oidd): sienta el oido hambre } \\
\text { a) (gusto): comer y beber. } \\
\text { b) (oido): los placeres del oído } \\
\text { c) (olfato) } \\
\text { c) (olfato): el atractivo de los perfumes. } \\
\text { d) (tacto): no sólo con el tacto... } \\
\text { e) (vista): vuessiros ojos no se fijen en mujer } \\
\text { d) (tacto): :elaciones sexuales y matrimonio } \\
\text { e) (vista): los deleites de los ojos }\end{array}$ \\
\hline & $\begin{array}{l}\overline{2} \\
3 \\
5\end{array}$ & $\begin{array}{l}\text { a) no buscar lo propio/buscar lo común } \\
\text { (envidia) } \\
\text { a) apropiarse los dones de Dios/no compar- } \\
\text { tirlos/(envidia) }\end{array}$ \\
\hline & 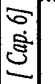 & $\begin{array}{l}\text { b) injuria/[ira//venganza } \\
\text { b) afrenta/[ira] venganza }\end{array}$ \\
\hline 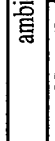 & हैं & $\begin{array}{l}\text { b) dominar con poder/busque más ser } \\
\text { amado que temido/dar cuenta a Dios } \\
\text { c) afán de dominio/ser temido y amadol } \\
\text { consecuencias en el juicio }\end{array}$ \\
\hline
\end{tabular}

Seccción C

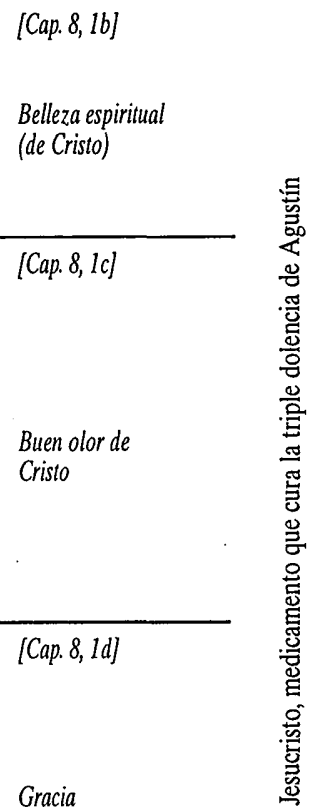

Esquema 3.

Con este esquema a la vista, es el momento de extraer las conclusiones.

Igual que respecto del $D V R$, los paralelismos, verbales o conceptuales, son tan evidentes que resulta difícil negar a) que, en su sección B y C, sobre todo teniendo en cuenta también los resultados de la comparación con DVR, la Regla está estructurada conforme al esquema de las tres concupiscencias; b) la coincidencia en la estructura entre el C10 y la Regla.

A partir de esta coincidencia estructural, es fácil dar el paso a la lógica interior de uno y otro escrito. La lógica que guía los desarrollos de C10 cabe 
formularla así: La unión permanente con Dios a que aspira san Agustín (sección A) es impedida por la triple concupiscencia (sección B) y posibilitada por la adhesión a Cristo (sección $\mathrm{C}$ ). Esta lógica aparece expresamente formulada en los capítulos 40 y 41 de C10. Primero señala que es habitual en él recorrer el camino de ascensión a Dios, descrito en la sección A:

«Y esto lo hago yo ahora muchas veces, y esto es mi deleite; y siempre que puedo desentenderme de los quehaceres forzosos, me refugio en este placer» 115 .

A continuación expone el resultado conseguido:

«A veces me introduces en un sentimiento interior muy inusitado, en una no sé qué dulzura interior que, si se completase en mí, no sé ya qué no sería esta vida. Pero con el peso de mis miserias vuelvo a caer en estas cosas terrenas y a ser reabsorbido por las cosas acostumbradas, quedando cautivo en ellas. Mucho lloro, pero mucho más soy detenido por ellas. ¡Tan grande es el poder de la costumbre! Aquí puedo estar y no quiero; allí quiero y no puedo. Infeliz en ambos casos» 116.

Luego concluye:

«Por lo cual, consideré mis dolencias (languores) pecaminosas bajo la triple forma de la concupiscencia e invoqué tu diestra con vistas a mi salvación» 117 .

San Agustín ha tenido una experiencia inicial y gozosa de Dios que le gustaría hacer definitiva. Pero el permanecer unido a Él le resulta inviable porque las «cosas acostumbradas» tiran de él hacia abajo. ¿A qué se refiere con esa expresión? Sin duda a las debilidades morales que tienen su origen en la triple concupiscencia. De ahí el «por lo cual» (ideoque). Tales debilidades constituyen el obstáculo para su permanente unión con Dios. Obstáculo que él por sí sólo no puede salvar, razón por la que, con igual lógica, reclama también la intervención de la Diestra de Dios, Cristo el Señor, del que hablará acto seguido en su función de mediador.

La misma lógica parece guiar la estructura de la Regla: el deseo de alcanzar (definitivamente) a Dios, expuesto en la sección A (in Deum), se ve, en un

115. «Et saepe istuc facio; hoc me delectat, et ab actionibus necessitatis, quantum relaxari possum, ad istam uoluptatem refugion (Conf. 10,40,65 CC 27,191).

116. «Et aliquando intromittis me in affectum multum inusitatum introrsus ad nescio quam dulcedinem, quae si perficiatur in me, nescio quid erit, quod uita ista non erit. Sed recedo in aerumnosis ponderibus et resorbeor solitis et teneor et multum fleo, sed multum teneor. Tantum consuetudinis sarcina digna est! Hic esse ualeo nec uolo, illic uolo nec ualeo, miser utrubique» (Conf. 10,40,65 CC 27,191).

117. «Ideoque consideraui languores peccatorum meorum in cupiditate triplici et dexteram tuam inuocaui ad salutem meam» (Conf. 10,41,66 CC 27,191). 
primer momento, obstaculizado por la existencia de las tres concupiscencias cuyos lazos y modo de romperlos expone en la sección $\mathrm{B}$, y, en un segundo momento, hecho posible por Jesucristo, presentado en la sección $\mathrm{C}$ como la alternativa auténtica y plenificante a lo ofertado por las concupiscencias de la sección anterior.

A nivel de estructura general, pues, $\mathrm{C} 10$ y la Regla coinciden en presentar, en el mismo orden incluso, tres momentos idénticos del camino espiritual, que se pueden simplificar en esta terna: objetivo, dificultad y posibilidad de superarla; o, utilizando un criterio cuantitativo, y en orden lógico, esta otra: privación, participación, plenitud. Pero la coincidencia no se agota en esa estructura general. $\mathrm{El}$ análisis anterior ha mostrado otras numerosas coincidencias en cada una de las secciones. Nos limitamos a enumerarlas. En cuanto a la sección A, coinciden en el movimiento hacia Dios. En cuanto a la sección $\mathrm{B}$, en su unidad primera, convergen en indicar que la oración puede ser interrumpida o turbada; en su unidad segunda, en la utilización del criterio de los sentidos; en su unidad tercera, en los males señalados o prevenidos: el de pretender dominar sobre los demás, el del modo de responder ante la ofensa, el de negarse a facilitar a los demás el disfrute de los dones recibidos de Dios. En cuanto a la sección $\mathrm{C}$, ambos escritos coinciden en su correlación con B y en su carácter cristológico.

Pero no se puede ocultar que, junto a las mencionadas coincidencias, existen también divergencias. En cuanto a la sección A, uno y otro escrito divergen en que en C10 no aparece el carácter cultual presente en la Regla $(1,8)$, debido a otro elemento divergente, a saber, la falta de carácter comunitario del movimiento hacia Dios. Aunque, en realidad, esta divergencia podría considerarse como inexistente, puesto que ambos elementos se hallan poco antes en la sección introductoria del libro.

En cuanto a la sección B, en su unidad primera, las divergencias están en el carácter genérico de C10 y más concreto de la Regla 118. En su unidad segunda, la Regla no recoge todos los sentidos, pues se echa de menos el del olfato ${ }^{119}$. En su unidad tercera, se advierte sobre todo la inversión en el orden: el orden a), b) y c) de C10 se transforma en la Regla en c), b) y a).

En cuanto a la sección $\mathrm{C}$, divergen en el carácter unitario de $\mathrm{C} 10$ que se limita a hablar de Cristo mediador que cura todas las dolencias, frente al

118. C10 constata las interrupciones y perturbaciones de la oración de forma genérica; R II, en cambio, señala, de un lado, que puede interrumpir o perturbar la oración privada quien en el oratorio esté haciendo algo no adecuado al lugar (II,2); de otro, se refiere en concreto al recitado de los salmos e himnos (II,3).

119. Aunque esta ausencia queda compensada por su aparición en la parte correlativa de la sección C. 
diversificado de la Regla (Cristo como Belleza que enamora, desprendiendo un perfume que encandila y donando la libertad respectivamente).

Ultima diferencia entre C10 y la Regla consiste en que en C10 san Agustín habla como «confesor» de cómo es él mismo; en la Regla, como legislador, de cómo deben ser los siervos de Dios. En C10 el santo nos informa sobre si él sucumbe o no en la prueba; en la Regla qué deben hacer los siervos de Dios para no sucumbir. Habla, sin duda, desde su experiencia personal, entendiéndola en doble sentido: lo que ha vivido él en su interior y lo que ha percibido en otros. Para comprender las divergencias entre ambos textos, dentro de otras convergencias, no se debe perder de vista el carácter de uno y otro: C10 es una «confesión», el otro una Regla monástica. Evidentemente no es lo mismo «confesar» que legislar. De nuevo tenemos la diferencia entre el aspecto cognoscitivo y el aspecto moral. El mal y su solución, el primer paso (B); luego, una motivación mayor (C).

Las convergencias y divergencias muestran que estamos ante un esquema, un recipiente que se puede llenar con diferentes materiales. Por tanto, no sería procedente buscar una coincidencia plena; en ese caso no habría hecho falta la otra obra, una vez escrita la primera. La Regla y C10 no son copia el uno del otro, pero sí reflejan un momento concreto de la evolución espiritual y teológica del santo.

\subsubsection{Comparación entre C10 y De vera religione}

Hemos comparado la Regla primero con el $D V R$ y luego con C10. Puede ser provechoso extender la comparación a ambos escritos entre sí, pero teniendo siempre el código monástico como tertium comparationis.

\subsubsection{Carácter general}

Hay que partir de que en san Agustín no cabe pensar en una separación neta entre filosofía y teología, como dos ciencias que corran paralelas. De ahí que sea con frecuencia difícil clasificar sus obras como simplemente filosóficas o simplemente teológicas. Es lo que acontece en los dos escritos que nos ocupan. De los trece libros de las Confesiones, el libro décimo y el undécimo, son los preferidos de los filósofos. Este por su análisis del tiempo, aquel por su adentrase en los últimos recovecos de la memoria y espíritu humano. Es, sin duda, una obra profundamente filosófica. Pero, limitándonos ahora a C10, no es menos cierto que es un escrito de rica teología. En cuanto a la obra DVR acontece algo parecido, aunque en menor grado. En cualquier clasifica- 
ción de las obras del santo se la ubica entre las filosóficas; pero tal obra sería imposible de comprender prescindiendo de un dato específicamente teológico como es la encarnación. Con todo, dentro del combinado de filosofía y teología que son una y otra obra, en C10 la teología tiene, en conjunto, mayor peso que en DVR. Por ejemplo en su sección $\mathrm{B}$, a propósito de las tres concupiscencias, $\mathrm{C} 10$ se remite exclusivamente a $1 \mathrm{Jn}$ 2,15-16; DVR, en cambio, en su situación $\mathrm{A}$, correlativa a la $\mathrm{B}$ de $\mathrm{C} 10$, utiliza otra terna, coincidente con la de san Juan en su contenido, pero difiere en la formulación; la de san Juan aparece sólo después como para validar la anterior. Asimismo la sección C de C10 tiene un formato más específicamente teológico que la correspondiente sección B de DVR. Aunque aquí apoye sus propuestas con textos bíblicos, el razonamiento se encuadra fácilmente en ámbito filosófico.

\subsubsection{Estructura general}

De lo general a lo particular: tal es el orden que vamos a seguir. De ahí que comencemos por la estructura en su sentido más global. Al respecto, se impone como primera constatación, la coincidencia en tres momentos, que dan origen a las tres primeras situaciones de DVR y a las tres secciones de $\mathrm{C} 10, \mathrm{y}$ que señalan el objetivo que se persigue, la dificultad que se encuentra y la posibilidad real de conseguirlo. Pero, frente a esa coincidencia, se constata, además, como divergencia, que el orden es diferente y, luego, que DVR cuenta con una situación más, la del fracaso.

Presentado en esquema:

DVR: dificultad (sección A), posibilidad (B), objetivo (logrado [C]/no logrado [D]).

C10: objetivo (sección A), dificultad (B), posibilidad (C).

El orden, más que ser casual, responde a distintas concepciones. El DVR presenta el recorrido abstracto del hombre, $\mathrm{C} 10$ el recorrido concreto de san Agustín. Hablando en general, en DVR, el santo presenta el final del recorrido con el doble destino posible; hablando de sí mismo, en $\mathrm{C} 10$, propone la meta que persigue, que no puede ser sino, al menos subjetivamente considerado, algo positivo. Por eso, al que hemos llamado objetivo de DVR sería más adecuado designarlo respectivamente «éxito» (objetivo logrado) o «fracaso» (objetivo no logrado), mientras que a propósito de $\mathrm{C} 10$ sería más propio hablar de ideal. Ahora bien, el ideal en cuanto tal se propone al inicio, aun- 
que se consiga al final; en cambio, el resultado se conoce al final, aunque se prevea al comienzo. De aquí la diferencia entre DVR y C10.

Si ahora volvemos los ojos a la Regla, no queda sino constatar la coincidencia plena con $\mathrm{C} 10$ en dos aspectos: en el orden y, como consecuencia de ello, en el hecho de presentar un ideal. Se comprende, pues, que tampoco ella aluda al momento del fracaso, porque nadie se propone como ideal fracasar en algo.

\subsubsection{Sección $A$ de $C 10$ y situación $C$ de DVR}

Esta sección recubre el «objetivo» en su doble forma de meta lograda y de ideal.

Establecido el distinto sentido que tienen en uno y otro texto, es el momento de comparar los respectivos contenidos. En primer lugar, aunque de entrada se perciba sólo la divergencia, en un examen atento se advierte la convergencia. La divergencia que se percibe se refiere a la diversificación del objetivo presentado por DVR, frente al carácter unitario del que propone C10. En DVR el objetivo logrado consiste en un conocimiento pleno, una salud plena y una paz plena; en C10 el ideal buscado consiste en la paz en Dios (in pacem tuam). Se advierte la convergencia porque el conocimiento, la salud y la paz plenos, tras de los que va el hombre según DVR, es imposible que el hombre los consiga desvinculado de Dios.

Pero existe otra divergencia más significativa: en DVR falta el aspecto comunitario que anotamos en $\mathrm{C} 10{ }^{120}$. En la primera obra cada cual parece moverse en solitario, en esta otra san Agustín quiere sentirse arropado por sus hermanos y él mismo actúa pensando en ellos.

También a este respecto la Regla está más cercana a C10 que a DVR. Con esta sólo tiene en común el que el objetivo se consigue en Dios; con aquella comparte, además, la presentación unificada de dicho objetivo (in pacem tuam/in deum) y el aspecto comunitario.

\subsubsection{Sección $B$ de C10 y situación $A$ de DVR}

Dentro de la simplificación establecida antes, esta sección hace frente al momento de «dificultad». La comparación con cada una de las unidades la establecemos por separado.

120. A los efectos, poco importa que no se halle en la designada como sección A, sino en la introdución. 
4.2.6.4.1. Unidad primera (cupiditas spectaculi / concupiscentia oculorum)

No es nuestro propósito analizar aquí con detalle la presentación que el santo hace en uno y otro texto de la cupiditas curiositatis o concupiscencia de los ojos. Baste decir que, dentro de una coincidencia global, cada texto mantiene su peculiaridad. Por encima de otros detalles ${ }^{121}$, la diferencia más significativa está en que, mientras DVR se coloca en el ámbito del conocimiento, C10 se ubica en el de la moral y espiritualidad. Con otras palabras, en DVR la curiosidad impide llegar a conocer al Dios verdadero -de ahí las falsas concepciones de Dios de los filósofos o de los maniqueos-; en C10 dicha concupiscencia impide el trato con Dios, ya conocido. DVR silencia el trato personal con Dios, C10 parte ya de su conocimiento; en DVR dicha concupiscencia es un impedimento para el buscador o pensador, en C10 para el orante.

De nuevo, el texto de la Regla se acerca más a C10 que a DVR. No por la terminología, pues al respecto se separa de los dos; sí por el contexto orante en que sitúa el acercamiento a la concupiscencia de los ojos.

\subsection{Unidad segunda (cupiditas voluptatis / concupiscentia carnis)}

La situación se repite aquí: coincidencia en la concepción global y divergencia al presentar las formas concretas de su manifestación. En DVR Agustín indica tres formas: el deseo de comer y beber, el deseo de satisfacer la sexualidad, el deseo de dormir; en C10, en cambio, presenta cinco, en relación con los cinco sentidos corporales.

En la Regla, como se ha visto, coexisten ambos modelos, pero ninguno en estado puro. Respecto al de DVR, el deseo de dormir está presente, pero tan diluido ya que apenas resulta perceptible. La diferencia se hace sensible con sólo considerar que, tanto al deseo de comer y beber como al de satisfacer el apetito sexual -en la Regla san Agustín mantiene el mismo orden que en DVR-, dedica respectivamente un capítulo, mientras al de dormir le concede -sin lógica que hayamos percibido-sólo una referencia perdida en medio del capítulo dedicado al primero de los deseos. Ya el DVR mostraba una cierta devaluación respecto de los otros dos, si es legítimo interpretar de esa manera el hecho de aparecer en tercer lugar.

121. Por ejemplo, a nivel de terminología: mientras DVR habla de phantasmata (imaginaciones), $\mathrm{C} 10$ habla de nugatoriae cogitationes (pensamientos fútiles), o de manifestaciones concretas: C10 presenta algunas silenciadas en DVR, por ej., el afán de presenciar monstra y miracula, el recurso a las artes mágicas, pedir milagros a Dios. 
En coincidencia con C10, la Regla acepta el criterio de los sentidos, pero tampoco plenamente; de un lado, silencia uno, el del olfato, hecho para el que ya adelantamos una explicación posible 122; de otro, cambia el orden, y hasta parece que quiere introducirlo de una manera un poco forzada en el esquema triádico de DVR, reducido ya en la práctica a una díada. Al deseo de comer y beber, asocia el sentido del gusto -cosa lógica- y el del oído, a través de la lectura como instrumento para alimentar el hombre interior ${ }^{123}$; al deseo de satisfacer el deseo sexual, a su vez, asocia el sentido del tacto, como es normal en él -al menos en la época en que escribe las Confessiones-, y el de la vista, fiel en ello al Sermón de la montaña. En este esquema binario doble (dos deseos, a cada uno de los cuales se asignan dos sentidos) no había cabida para el sentido del olfato, razón posible por la que, en la Regla, lo trasladó a la sección C.

En conclusión, con sólo estos datos ante los ojos, se podría decir que la Regla aparece como momento de transición de DVR a C10; el esquema anterior se mantiene, modificado ciertamente; el nuevo aparece pero no en su forma pura.

\subsection{Unidad tercera (voluptas excellentiae / ambitio saeculi)}

Como en las demás concupiscencias, también respecto a la tercera, en DVR san Agustín se detiene más en el aspecto teórico, y en C10 más en los aspectos concretos. A nivel teórico el planteamiento es globalmente coincidente; las divergencias aparecen a la hora de presentar las manifestaciones prácticas. La primera diferencia tiene carácter cuantitativo. Al analizar DVR señalamos sólo dos manifestaciones de esta tercera concupiscencia: la envidia y la ira; al analizar C10 ya encontramos tres: a la ira ${ }^{124}$ y la envidia -en el mismo orden que DVR-, antepone el afán de dominio sobre los otros desde el ejercicio de la autoridad (potestas). A este añadido se encuentra fácil explicación: sin desearlo ni buscarlo, más aún, tratando de evitarlo, san Agustín se encontró teniendo que ejercer el ministerio, y con él la autoridad, dentro de su comunidad eclesial, primero como presbítero y luego como obispo. Muy pronto pudo experimentar en propias carnes el peligro que de ahí le llegaba ${ }^{125}$. Al conside-

122. Cf. pág. 247.

123. O a través del canto. Cf. R II,4 y antes nota 33 .

124. Cf. págs. 240-241.

125. Cf. L. VeRHEIJEN, Saint Augustin, Un moine devenu prêtre et evêque, NA I, p. 266-270; ¿Por qué lloró san Agustín, cuando fue ordenado sacerdote?, en La búsqueda de Dios, Publicaciones agustinianas, Roma 1981, 201-204. 
rar la ambición mundana, desde la experiencia personal, el santo no puede olvidar ese nuevo aspecto, que cuando escribió DVR quizá no le preocupaba, ya porque no era problema para el destinatario de la obra, el amigo y mecenas Romaniano, ya porque no lo era para él personalmente. Decimos que quizá no le preocupaba, no que lo desconociera, puesto que ese aspecto ya lo toma en consideración en la «primera» Regla (De ordine 2,8,25ss) ${ }^{126}$.

La Regla se pone netamente de parte de C10 y se separa del DVR al incluir también, como manifestación de la ambición mundana, el peligro del afán de dominio sobre los demás en la persona constituida en autoridad. En cuanto al orden, la Regla sigue el propio (envidia, ira, y afán de dominio) frente al seguido conjuntamente por DVR y C10 ([afán de dominar], ira ${ }^{127}$ y envidia).

Teniendo en cuenta que en DVR falta ese afán de dominio, el haberlo introducido en la Regla, indica posiblemente, que san Agustín ya se sentía afectado de alguna manera por dicho problema. El dato podría ofrecer un criterio para fechar el documento, pero en la práctica es de mínima utilidad. Podría servir ciertamente si esa conciencia la hubiera adquirido con el ascenso al episcopado, que ciertamente le otorgaba esa potestas eclesiástica -y en ciertos aspectos también civil-. Pero la lectura de la carta 22 al obispo de Cartago Aurelio, del año 392, muy poco después por tanto de la composición del DVR, deja bien claro que tal conciencia le acompañó ya desde los primeros momentos del ejercicio del ministerio de presbítero ${ }^{128}$. Dejando de lado las consideraciones de carácter general y, por tanto, válidas para los clérigos como colectivo, trascribimos únicamente la confesión que hace a propósito de sí mismo:

«Si verdaderamente se nos alaba en atención a Dios, congratulémonos con aquellos a quienes gusta el bien verdadero, y no con nosotros mismos por el hecho de agradar a los hombres; pero siempre que, en presencia de Dios, seamos tales como nos suponen, y las alabanzas que se tributan con verdad y razón, no se nos atribuyan a nosotros, sino a Dios, cuyos son todos los bienes. Estas cosas me las digo a mí mismo a diario o, mejor, me las dice aquel cuyos son los laudables preceptos que se hallan en las divinas lecturas o son sugeridos interiormente al alma. A diario lucho con mi adversario y con frecuencia recibo he-

126. Cf. L. VerheIJEN, «Vers la beauté spirituelle» (Par les praecepta uiuendi à la spiritalis pulchritudo. «Pythagore», le De Ordine de saint Augustin et sa Règle), en Augustiniana 22 (1972) 469-470; NA I, 201-202.

127. Ponemos ese orden por aparecer así la primera vez; pero en DVR el desarrollo más amplio, corresponde, con diferencia, a la envidia.

128. Cf. L. VERHEIJEN, Saint Augustin, Un moine devenu prêtre et evêque, NA I, 270-274. 
ridas, cuando no puedo reprimir la complacencia ante la lisonja que me tributan» 129 .

Ciertamente no habla del afán de dominio, pero el contenido está en la misma línea de lo confesado en $\mathrm{C} 10$.

\subsubsection{Sección $C$ de C10 y situación $B$ de DVR}

La última sección, recuérdese, corresponde al momento de posibilidad, o -con otro criterio- de la posesión parcial, la etapa entre la dificultad y el objetivo. Representa el paso intermedio entre la nada y la plenitud; la etapa de los logros provisionales, que permite mirar el futuro con esperanza. Tales logros, en efecto, a la vez que indican que es posible vencer la dificultad, encienden aún más el deseo de la plenitud.

La divergencia es aquí más patente que la convergencia. Lo primero que se percibe es que C10 abandona el criterio diversificador de DVR en favor de otro unificador. Lo segundo, que DVR habla de realidades, mientras C10 habla de una persona; DVR expone cómo son objetivamente las cosas, mientras que en C10 san Agustín se ocupa del aspecto subjetivo, de cómo es él mismo. De otra parte, DVR habla desde la positividad, C10 desde la negatividad. Es decir, DVR presenta la belleza, percibida interiormente, de la Verdad y la Sabiduría, como alternativa a la belleza exterior con que se satisface la curiosidad; una sensación placentera de Dios, como alternativa a las sensaciones nulas o pobremente gratificantes de los sentidos exteriores, y una libertad parcial, como alternativa a la esclavitud a que conduce el orgullo; $\mathrm{C} 10$, en cambio, presenta a Cristo como único mediador y médico que cura las dolencias dejadas por la rendición a la triple concupiscencia. La realidad última es la misma: la liberación, aún parcial, del triple mal del deseo pervertido. Pero los acentos son distintos: DVR prefiere presentar el hecho objetivo; $\mathrm{C} 10$ sobre todo al autor del hecho, Cristo; además, C10 no contempla la nueva situación desde el punto de llegada, es decir, desde lo logrado (positividad del DVR), sino desde el punto de partida, esto es, desde el mal de que se libró («negatividad» de C10). Para concluir, una nueva divergencia: en

129. «Si autem merito laudamur propter deum, gratulemur eis, quibus placet uerum bonum, non tamen nobis, quia placemus hominibus, sed si coram deo tales sumus, quales esse nos credunt, et non tribuitur nobis sed deo, cuius dona sunt omnia, quae uere meritoque laudantur. haec mihi ipse canto cotidie uel potius ille, cuius salutaria praecepta sunt, quaecumque siue in diuinis lectionibus inueniuntur siue quae intrinsecus animo suggeruntur. et tamen vehementer cum aduersario dimicans saepe ab eo uulnera accipio, cum delectationem oblatae laudis mihi auferre non possum» (Epist. 22,2,8 CSEL 34/1,61). 
DVR esta etapa es genéricamente «teológica», en C10 es específicamente cristológica 130.

Con referencia a esta sección, la Regla se encuentra en el paso de la presentación propia de un texto a la del otro. En conjunto, se siente más cercano el DVR que C10, pero ya se intuye el cambio. De un lado mantiene el criterio diferenciador y presenta realidades objetivas (belleza, olor, libertad); de otro, ya asoma Cristo como criterio unificador; mencionado explícitamente a propósito de la segunda unidad, se advierte su presencia oculta en las otras dos unidades; en una, como poseedor de la belleza espiritual; en otra, como agente que otorga libertad.

Entre DVR y C10 se halla C9, texto que puede contener una buena clave de interpretación del texto de la Regla. Como ocupará nuestra atención en el apartado siguiente, no es preciso detenernos ahora en él.

(continuará)

Pío DE LuIS

Estudio Teológico Agustiniano

Valladolid

130. Con esta formulación en ningún modo pretendemos separar la cristología de la teología. 